\title{
Short-Term Plasticity Combines with Excitation-Inhibition Balance to Expand Cerebellar Purkinje Cell Dynamic Range
}

\author{
Anais Grangeray-Vilmint, ${ }^{1}{ }^{\circledR}$ Antoine M. Valera, ${ }^{1}{ }^{\circledR}$ Arvind Kumar, ${ }^{2 \star}$ and $\odot$ Philippe Isope ${ }^{1 \star}$ \\ ${ }^{1}$ Institut des Neurosciences Cellulaires et Intégratives, Centre National de la Recherche Scientifique, Université de Strasbourg, 67084 Strasbourg, France and \\ ${ }^{2}$ Department of Computational Science and Technology, School of Electrical Engineering and Computer Science, KTH Royal Institute of Technology, 11428 \\ Stockholm, Sweden
}

The balance between excitation (E) and inhibition (I) in neuronal networks controls the firing rate of principal cells through simple network organization, such as feedforward inhibitory circuits. Here, we demonstrate in male mice, that at the granule cell $(\mathrm{GrC})$ molecular layer interneuron (MLI)-Purkinje cell (PC) pathway of the cerebellar cortex, E/I balance is dynamically controlled by shortterm dynamics during bursts of stimuli, shaping cerebellar output. Using a combination of electrophysiological recordings, optogenetic stimulation, and modeling, we describe the wide range of bidirectional changes in PC discharge triggered by GrC bursts, from robust excitation to complete inhibition. At high frequency $(200 \mathrm{~Hz})$, increasing the number of pulses in a burst (from 3 to 7$)$ can switch a net inhibition of PC to a net excitation. Measurements of EPSCs and IPSCs during bursts and modeling showed that this feature can be explained by the interplay between short-term dynamics of the GrC-MLI-PC pathway and E/I balance impinging on PC. Our findings demonstrate that $\mathrm{PC}$ firing rate is highly sensitive to the duration of GrC bursts, which may define a temporal-to-rate code transformation in the cerebellar cortex.

Key words: excitation-inhibition balance; burst coding; feedforward inhibition; Purkinje cell; short-term dynamics

Significance Statement

Sensorimotor information processing in the cerebellar cortex leads to the occurrence of a sequence of synaptic excitation and inhibition in Purkinje cells. Granule cells convey direct excitatory inputs and indirect inhibitory inputs to the Purkinje cells, through molecular layer interneurons, forming a feedforward inhibitory pathway. Using electrophysiological recordings, optogenetic stimulation, and mathematical modeling, we found that presynaptic short-term dynamics affect the balance between synaptic excitation and inhibition on Purkinje cells during high-frequency bursts and can reverse the sign of granule cell influence on Purkinje cell discharge when burst duration increases. We conclude that short-term dynamics may play an important role in transforming the duration of sensory inputs arriving on cerebellar granule cells into cerebellar cortical output firing rate.

\section{Introduction}

The feedforward inhibition (FFI) circuit is an ubiquitous motif in the brain. In FFI pathways, an external excitatory input impinges on both a principal cell and local inhibitory interneurons that

\footnotetext{
Received Nov. 17, 2017; revised April 11, 2018; accepted April 21, 2018.

Author contributions: A.G.-V. wrote the first draft of the paper; A.M.V. edited the paper; A.K. and P.I. designed research; A.G.-V. performed research; A.M.V. and A.K. contributed unpublished reagents/analytic tools; A.G.-V., A.K., and P.I. analyzed data; A.K. and P.I. wrote the paper.

This work was supported by the Centre National pour la Recherche Scientifique, Université de Strasbourg, Agence Nationale pour la Recherche Grant ANR-15-CE37-0001-01 CeMod, and Fondation pour la Recherche Médicale DEQ20140329514 to P.I., A.G.-V., and A.M.V. were supported by a fellowship from the Ministère de la Recherche. A.M.V. was also supported by Fondation pour la Recherche Médicale fellowship. A.K. was supported in part by the Parkinsonfonden Sweden and the Strategic Research Area Neuroscience (StratNeuro) program of Sweden. We thank Bernard Poulain and Matilde Cordero-Erausquin for critical discussions and readings; Kevin Dorgans and Frédéric Doussau for critical readings; Thomas J. Younts, Alex Cayco Gajic, and Harsha Gurnani for proofreading; and Sophie Reibel-Foisset and the Chronobiotron UMS 3415 for mice handling.

The authors declare no competing financial interests.

${ }^{*}$ A.K. and P.I. contributed equally to this work.
}

also target the principal cell. That is, an external input elicits an excitation (E) which is quickly followed by an inhibition (I) in the principal cell. FFI circuit properties have been extensively studied (for review, see Isaacson and Scanziani, 2011). In vivo, in vitro, and computational modeling studies of FFI circuits have shown that the balance and relative timing of $\mathrm{E}$ and I inputs are crucial in shaping the temporal window for spike discharge and the selective gating of stimulus-related activity (Wehr and Zador, 2003;

Correspondence should be addressed to either of the following: Dr. Philippe Isope, Institut des Neurosciences Cellulaires et Intégratives, Centre National de la Recherche Scientifique, Université de Strasbourg, 67084 Strasbourg, France, E-mail: philippe.isope@inci-cnrs.unistra.fr; or Dr. Arvind Kumar, Department of Computational Science and Technology, School of Electrical Engineering and Computer Science, KTH Royal Institute of Technology, 11428 Stockholm, Sweden, E-mail: arvkumar@kth.se.

A.M. Valera's present address: Department of Neuroscience, Physiology and Pharmacology, University College London, London, United Kingdom.

D0I:10.1523/JNEUROSCI.3270-17.2018

Copyright $\odot 2018$ the authors $\quad 0270-6474 / 18 / 385153-15 \$ 15.00 / 0$ 
Gabernet et al., 2005; Mittmann et al., 2005; Kremkow et al., 2010; Katzner et al., 2011; Bartley and Dobrunz, 2015). Moreover, correlated $\mathrm{E}$ and I inputs can prevent saturation of the postsynaptic spiking activity as well as extend the dynamic range for stimulus rate coding (Eccles et al., 1967; Buzsáki, 1984; Shepherd and Grillner, 2010; Isaacson and Scanziani, 2011). Another ubiquitous property of the brain is that almost all synapses show presynaptic short-term dynamics (STD) (Atluri and Regehr, 1996; Valera et al., 2012; Jackman and Regehr, 2017). Indeed, the size of the postsynaptic potential (PSP) can increase or decrease depending on the incoming spike history and presynaptic plasticity (Stevens and Wang, 1995; Markram and Tsodyks, 1996; Zucker and Regehr, 2002). Thus, the STD of synapses may strongly affect the $\mathrm{E} / \mathrm{I}$ ratio and signal integration at the principal cell as the input firing rate increases.

The cerebellum computes a wide range of sensorimotor information, including very high-frequency bursts of action potentials $(>100 \mathrm{~Hz})$ through the mossy fiber (MF)-granule cell $(\mathrm{GrC})-$ molecular layer interneurons (MLI)-Purkinje cell (PC) network, which constitutes a typical FFI pathway (Eccles et al., 1967; van Kan et al., 1993; Brunel et al., 2004; Chadderton et al., 2004; Mittmann et al., 2005; Jörntell and Ekerot, 2006; Saviane and Silver, 2006; Rancz et al., 2007; Arenz et al., 2008; van Beugen et al., 2013; Jelitai et al., 2016). PCs encode whisker position (Chen et al., 2016) or different features of locomotion (Sauerbrei et al., 2015) through a bidirectional modulation of their spontaneous firing rate (Häusser and Clark, 1997). Therefore, STD should have a strong effect on PC output and information transfer via the cerebellar FFI. However, how the interplay between E/I balance and STD at the GrC-MLI-PC synapses affect the PC discharge has not been well characterized and understood.

Here, we combine in vitro electrophysiological recordings with numerical simulation of the GrC-MLI-PC pathway to understand how E/I balance and synaptic STD influence the encoding of spike burst inputs in the PC output spike patterns. We show that the diversity of the PC output firing rate is governed not only by the E/I balance but also by the STD of the synapses. Notably, we demonstrate that because of synaptic STD, even the stimulus duration can determine the sign of the spike gain of the PC firing rate. This property of the cerebellar FFI may underlie the structured variability observed during locomotion (Sauerbrei et al., 2015) and help us understand the bidirectional modulation of the PC firing rates observed in behaving animals.

\section{Materials and Methods}

All procedures were in accordance with national and European community guidelines (2010/63/EU). Animal experimentations were approved in advance by the local French Ethics Committee of Strasbourg (CREMEAS; CEEA35; agreement number/reference protocol: A672018-38). Mice were bred and housed in a $12 \mathrm{~h}$ light/dark cycle with free access to food and water. The 3- to 8-week-old male heterozygous Thy1ChR2-eYFP mice (B6.Cg-Tg(Thy1-COP4/EYFP)18Gfng/J from The Jackson Laboratory, IMSR catalog \#JAX:007612, RRID:IMSR_JAX: 007612) were used (Arenkiel et al., 2007).

\section{Electrophysiology}

Slice preparation. Mice were decapitated under isoflurane anesthesia. The cerebellum was dissected out and quickly placed in a $4^{\circ} \mathrm{C}$ ACSF bubbled with carbogen $\left(95 \% \mathrm{O}_{2}, 5 \% \mathrm{CO}_{2}\right)$. ACSF was composed of the following (in mM): $120 \mathrm{NaCl}, 3 \mathrm{KCl}, 26 \mathrm{NaHCO}_{3}, 1.25 \mathrm{NaH}_{2} \mathrm{PO}_{4}, 2 \mathrm{CaCl}_{2}, 1 \mathrm{MgCl}_{2}$, 20 glucose, 0.00005 minocycline. Transverse slices of $300 \mu \mathrm{m}$ thickness were then prepared (Vibratome Microm HM 650V) in an ice-cold potassium-based medium containing the following (in mM): K-gluconate 130, $\mathrm{KCl}$ 14.6, EGTA 2, HEPES 20, glucose 25, minocycline 0.00005, and 1 kynurenic acid. To allow metabolic reactivation of the cells, slices were soaked in a sucrose-based medium at $34^{\circ} \mathrm{C}$, containing the following (in $\mathrm{mm}$ ): sucrose 230, $\mathrm{KCl} 2.5, \mathrm{NaHCO}_{3} 26, \mathrm{NaH}_{2} \mathrm{PO}_{4} 1.25$, glucose 25 , $\mathrm{CaCl}_{2} 0.8, \mathrm{MgCl}_{2} 8$, minocycline 0.00005 , and D-APV 0.05 before being transferred and maintained in ACSF medium at least $1 \mathrm{~h}$ before electrophysiological recordings. Slices were transferred to a submerged recording chamber under the microscope (BX61 Olympus) and perfused with oxygenated ACSF.

Recordings. All recordings were located in the anterior part of the vermis (lobules III-VI) and performed at near physiological temperature $\left(32 \pm 0.5^{\circ} \mathrm{C}\right)$. Recorded PCs were visually identified under infrared illumination. PC discharge was initially monitored using extracellular recordings with pipettes filled with $0.5 \mathrm{M} \mathrm{NaCl}($ resistance $=15-30 \mathrm{M} \Omega$ ). PCs were located 50-75 $\mu \mathrm{m}$ beneath the slice surface to ensure the preservation of the FFI. PCs were then whole-cell voltage-clamped (Axopatch 200A or Multiclamp 700B, Molecular Devices) using 3-4 M $\Omega$ pipettes. All the data were acquired using WinWCP 4.5.4 freeware (John Dempster, University of Strathclyde, Glasgow, UK; RRID:SCR_014713). Recordings were sampled at $50 \mathrm{kHz}$ and filtered at $2 \mathrm{kHz}$. Currents were recorded using the following pipette internal solution (in mM): $135 \mathrm{KMeSO}_{4}, 6$ $\mathrm{NaCl}, 10$ HEPES, $4 \mathrm{MgATP}, 0.4 \mathrm{Na}_{2} \mathrm{GTP}, 1 \mathrm{MgCl}_{2}$ with $\mathrm{pH}$ adjusted to 7.3 with $\mathrm{KOH}$ (osmolarity to $300 \mathrm{mOsm}$ ). For E/I ratios measurements, PCs were successively voltage-clamped at $-60 \mathrm{mV}$ and then $0 \mathrm{mV}$ to measure EPSCs and IPSCs, respectively. Series resistance was monitored and compensated ( $80 \%$ typically) in all experiments. Voltages were not corrected for the liquid junction potential, which was calculated to be 9 $\mathrm{mV}$. We accepted recordings for which the leak current at $-60 \mathrm{mV}$ did not exceed $1 \mathrm{nA}$. When possible, STD were estimated after extracellular recordings and $\mathrm{E} / \mathrm{I}$ ratio measurements. Bursts of $\operatorname{GrC}$ stimuli $(1,3$, and 7 stimuli) were then elicited (see below). STD were also measured in a dedicated set of experiments. PCs were whole-cell recorded, and stimulation intensity was calibrated to evoke an initial EPSC of $\sim 100 \mathrm{pA}$. A 7-step protocol was performed in which sequences of 1-7 stimuli were applied (see Data analysis). In these experiments, the internal solution contained the following (in mM): $135 \mathrm{CsMeSO}_{4}, 6 \mathrm{NaCl}, 10$ HEPES, 4 MgATP, 1 EGTA, $0.4 \mathrm{Na}_{2} \mathrm{GTP}, 1 \mathrm{MgCl}_{2} \cdot 6 \mathrm{H}_{2} \mathrm{O}$, and 5 QX-314. pH was adjusted to 7.3 with $\mathrm{CsOH}$ and osmolarity was set to $290 \mathrm{mOsm}$. All chemicals were supplied by Sigma-Aldrich and Tocris Bioscience.

$\mathrm{GrC}$ stimulation. GrC firing patterns were reproduced in acute cerebellar slices using extracellular electrical stimulation of groups of $\mathrm{GrC}$ somas with a glass pipette filled with HEPES-buffered saline connected to an electrical stimulator (ISO-STIM 01D, NPI Electronic). HEPES-buffered saline contained the following (in $\mathrm{mM}$ ): $\mathrm{NaCl} \mathrm{120,} \mathrm{KCl} \mathrm{3,} \mathrm{HEPES} \mathrm{10,}$ $\mathrm{NaH}_{2} \mathrm{PO}_{4} 1.25, \mathrm{CaCl}_{2} 2, \mathrm{MgCl}_{2} 1$, glucose 10 . Stimulated GrCs were located at a lateral distance of $100-300 \mu \mathrm{m}$ from the recorded PC. Stimulation intensity ( $70 \mu \mathrm{A}$ to $1 \mathrm{~mA}, 20 \mu \mathrm{s}$ ) was adjusted to alter PC discharge after a single stimulus and bursts of 1,3 , and 7 stimuli at $200 \mathrm{~Hz}$ were performed every $30 \mathrm{~s}$.

\section{Optical stimulation}

Thy1-ChR2-eYFP strain of mice expresses Channelrhodopsin2 in MFs. MFs were photo-stimulated in acute slices using $470 \mathrm{~nm}$ LED-based illumination (collimated LED M470L2-C1 powered by a T-cube LEDD1B driver, Thorlabs) through the objective $(40 \times)$. LED pulses were driven by a digital waveform generated using Igor Pro version 6.32A (Wavemetrics; RRID: SCR_000325). Illumination was composed of pulses (5 ms) of blue light triggered at random instantaneous frequencies during each trial. Illumination intensities $\left(1-5 \mathrm{~mW} / \mathrm{mm}^{2}\right)$ were set in each experiment to increase the irregularity of Purkinje cell discharge as monitored by the CV2 value (see below).

\section{Pharmacology}

To limit plasticity induction during our protocols, we blocked NMDA, adenosine, $\mathrm{CB}_{1}, \mathrm{GABA}_{\mathrm{B}}$, and $\mathrm{mGluR}_{1}$ receptors by adding the following antagonists, respectively (in mM): 0.05 D-AP5, 0.0005 DPCPX (8-cyclopentyl-1,3-dipropylxanthine), 0.001 AM251 ( $N$-(piperidin-1-yl)-5-(4-iodophenyl)-1-(2,4-dichlorophenyl)-4-methyl-1 H-pyrazole-3-carboxamide), 0.001 CGP52432 (3-[[(3,4-dichlorophenyl)-methyl]amino]propyl 
(diethoxymethyl) phosphinic acid), and 0.002 JNJ16259685(3,4-dihydro$2 H$-pyrano[2,3] $\beta$-quinolin-7-yl)(cis-4-methoxycyclohexyl) methanone). In a subset of experiments, inhibitory transmission was blocked using picrotoxin $(100 \mu \mathrm{M})$, a $\mathrm{GABA}_{\mathrm{A}}$ receptor antagonist. Except for picrotoxin (Sigma-Aldrich), all drugs were supplied by Tocris Bioscience.

\section{Data analysis}

Extracellular recordings. In extracellular recordings, action potentials were detected using OpenElectrophy, an open source software (http:// neuralensemble.org/OpenElectrophy/; RRID:SCR_000819) (Garcia and Fourcaud-Trocmé, 2009). Data were stored in SQL databases (Oracle). Spike trains were analyzed using Python software written in-house (SynaptiQs developed by Antoine Valera) and custom-based routines. PC discharge irregularity was assessed by two parameters: (1) the coefficient of variation for adjacent interspike intervals (ISIs) (CV2) calculated as follows:

$$
\mathrm{CV} 2=2 \frac{\left|\mathrm{ISI}_{n+1}-\mathrm{ISI}_{n}\right|}{\left|\mathrm{ISI}_{n+1}+\mathrm{ISI}_{n}\right|}
$$

where ISI $_{n}$ is the ISI containing the stimulation. (2) Because PCs are spontaneously active and display a wide range of firing frequencies, we also determined the frequency-independent local variation of ISIs with a refractory period $R(L v R)$ (Kumbhare and Baron, 2015) as follows:

$$
\begin{aligned}
L v R=\frac{3}{n-1} \sum_{i=1}^{n-1}\left(1-\frac{4 \mathrm{ISI}_{i} \mathrm{ISI}_{i+1}}{\left(\mathrm{ISI}_{i}+\mathrm{ISI}_{i+1}\right)^{2}}\right) & \\
& \times\left(1+\frac{4 \mathrm{R}}{\mathrm{ISI}_{\mathrm{i}}+\mathrm{ISI}_{\mathrm{i}+1}}\right), \text { with } R=5 \mathrm{~ms}
\end{aligned}
$$

Subthreshold GrC stimulation was assessed using the peristimulus time histogram (PSTH) of PCs responses to a single stimulation. The $1 \mathrm{~ms}$ bin width PSTHs were built by aligning at least 30 consecutive trials on the stimulus onset and by calculating the spike probability in each bin. GrC stimulations inducing an initial increase in spike probability exceeding 0.8 in a time bin of $5 \mathrm{~ms}$ after the stimulation were excluded as they correspond to suprathreshold inputs likely to be beyond the physiological range determined in vivo (Bower and Woolston, 1983; Jaeger and Bower, 1994; Mittmann and Häusser, 2007; Wilms and Häusser, 2015).

Spike gain. The spike gain of PC discharges was determined as follows (see Fig. 1E) (Mittmann and Häusser, 2007): (1) the mean PSTH was computed from all the trials of each type of $\mathrm{GrC}$ stimulation $(1,3$, and 7 stimuli); (2) the baseline level was subtracted from the mean PSTH; and (3) the spike gain is given by the cumulative sum (with a bin size of $5 \mathrm{~ms}$ ) of the number of spikes exceeding or below the baseline. Therefore, the spike gain corresponds to the overall effect of the $\mathrm{GrC}$ stimulation and is not limited to the time window of the stimulation ( $10 \mathrm{~ms}$ for 3 stimuli and $30 \mathrm{~ms}$ for 7 stimuli).

E/I ratio and STD measurements. EPSCs and IPSCs were recorded in whole-cell (see above), and measurements were made after averaging at least 20 traces. E/I was calculated as the ratio of EPSCs and IPSCs amplitude in response to a single GrC stimulation. EPSC-IPSC delay was determined by subtracting the EPSC and IPSC latencies measured between the stimulation artifact and 10\% of EPSC/IPSC amplitude. For STD measurements, after extracellular recordings, amplitudes were measured between the peak and the extrapolation of the residual current from EPSC $_{n-1}$ or IPSC $\mathrm{n}_{-1}$ after fitting with a monoexponential function. Amplitudes of evoked postsynaptic currents (PSCs) resulting from the $n^{\text {th }}$ stimulus were defined as $\mathrm{EPSC}_{n}$ and $\mathrm{IPSC}_{n}$. STD was calculated as follows:

$$
\mathrm{STD} n=\frac{\text { mean } \mathrm{PSC}_{\mathrm{n}}}{\text { mean } \mathrm{PSC}_{1}}
$$

In a dedicated set of experiments (see recordings) for STD measurements, $\mathrm{GrC}$ stimulations were delivered in a sequence of $1,2,3 \ldots 7$ pulses, and the amplitude of the $n^{\text {th }}$ PSC was estimated by subtraction of the recordings with $n^{\text {th }}-1$ stimulations.

Principal component analysis (PCA) and hierarchical cluster analysis. PCA and hierarchical cluster analysis were performed using FactoMineR plug-in in Ri386 3.2.2 software developed by François Husson (Lê et al., 2008; Husson et al., 2016) (RRID:SCR_014602). The 12 following variables were used for the PCA: the number of additional spikes or omitted spikes in response to 3 and 7 stimuli (Add3, Add7, Om3, Om7), the duration of these phases (AddDur3, AddDur7, OmDur3, OmDur7), the net spike output (spike gain) after 3 and 7 stimuli (Net3, Net7), and the EPSC and IPSC amplitude (see Fig. 3A). Variables were centered and reduced. The first two principal components with the higher variance (dimension 1, 52.76\%; dimension 2, 15.1\%) were considered and used for the hierarchical clustering algorithm (Ward's method, http://factominer.free.fr/factomethods/ hierarchical-clustering-on-principal-components.html). The number of clusters in the hierarchical tree was set at 3 , a value above which the gain in intergroup variance was minimal (see Fig. $3 C$, inset).

\section{Simulation}

$P C$ neuron. Membrane current is calculated using the following equation:

$$
C_{m} \frac{d V_{m}}{d t}=g_{\text {leak }}\left(V m-E_{\text {leak }}\right)+I_{s y n}^{\text {exc }}(t)+I_{s y n}^{\text {inh }}(t)+I_{\text {ext }}(t)
$$

where $C m$ is the membrane capacitance, $g_{\text {leak }}$ is the leak conductance, and $E_{\text {leak }}$ is the resting potential of the neuron. $I_{s y n}^{\text {exc }}(t)$ represents the total excitatory inputs arriving from the GrCs, and $I_{s y n}^{\text {inh }}(t)$ represents the total inhibitory inputs arriving from the inhibitory interneurons. In the absence of any specific stimulus PC spike at $\approx 30 \mathrm{~Hz}$ in a quasi-periodic manner $\left(C V_{i s i} \approx 0.2\right)$. To mimic this ongoing activity in our simple point neuron model of the PC, we injected noisy excitatory current, $I_{\text {ext }}(t)$, corresponding to a spike train drawn from a sinusoidally modulated $\Gamma$-process (frequency $=37 \mathrm{~Hz}$; order $=4$ ). The magnitude of the sinusoidal modulation was $10 \%$ of the average input rate, which was set to 2000 spikes/s to obtain 30 spikes/s as the output firing rate in the model neuron. For each trial, we used a different realization of the sinusoidally modulated $\Gamma$-process to generate the background activity in the PC. This model clearly is an oversimplification of the dynamics of PCs. Still, this simple model allows us to study the effect of synaptic dynamics on the integration of external input by a feedforward inhibitory circuit motif. Complex nonlinear dynamics of PCs could have obscured these synaptic effects.

Synapse model. Synapses were modeled as a conductance transient as follows:

$$
I_{s y n}^{a}(t)=S_{a}(t)\left(V m(t)-E_{a}^{r e v}\right)
$$

where $S_{a}(t)(a \in\{$ exc., inh. $\})$ is the synaptic transient, $V_{\mathrm{m}}$ is the membrane potential, and $E_{a}^{r e v}$ is the reversal potential of the synapse (for the parameters, see Table 2). Each presynaptic spike induced an $\alpha$ functionshaped conductance transient in the postsynaptic PC as follows:

$$
S_{a}(t)=J_{a}(t) \times \frac{t}{\tau_{a}} \exp \left(-\frac{t}{\tau_{a}}\right)
$$

where $\tau_{\mathrm{a}}$ is the synaptic time constant and $J_{a}(t)$ is the amplitude of the synapse. When synapses are static, $J_{a}(t)$ is constant; and when synapses change according to the history of the previous presynaptic spikes, the temporal evolution of $J_{a}(t)$ is given by Equation 8 . To model the STD of the PSP amplitude, we used a deterministic model proposed by Tsodyks and Markram (1997).

$$
\begin{gathered}
\frac{d x_{a}}{d t}=\frac{z_{a}}{\tau_{r e c}}-u_{a} x_{a} \delta\left(t-t^{s p i k e}\right) \\
\frac{d y_{a}}{d t}=-\frac{y_{a}}{\tau_{I}}-u_{a} x_{a} \delta\left(t-t^{s p i k e}\right)
\end{gathered}
$$



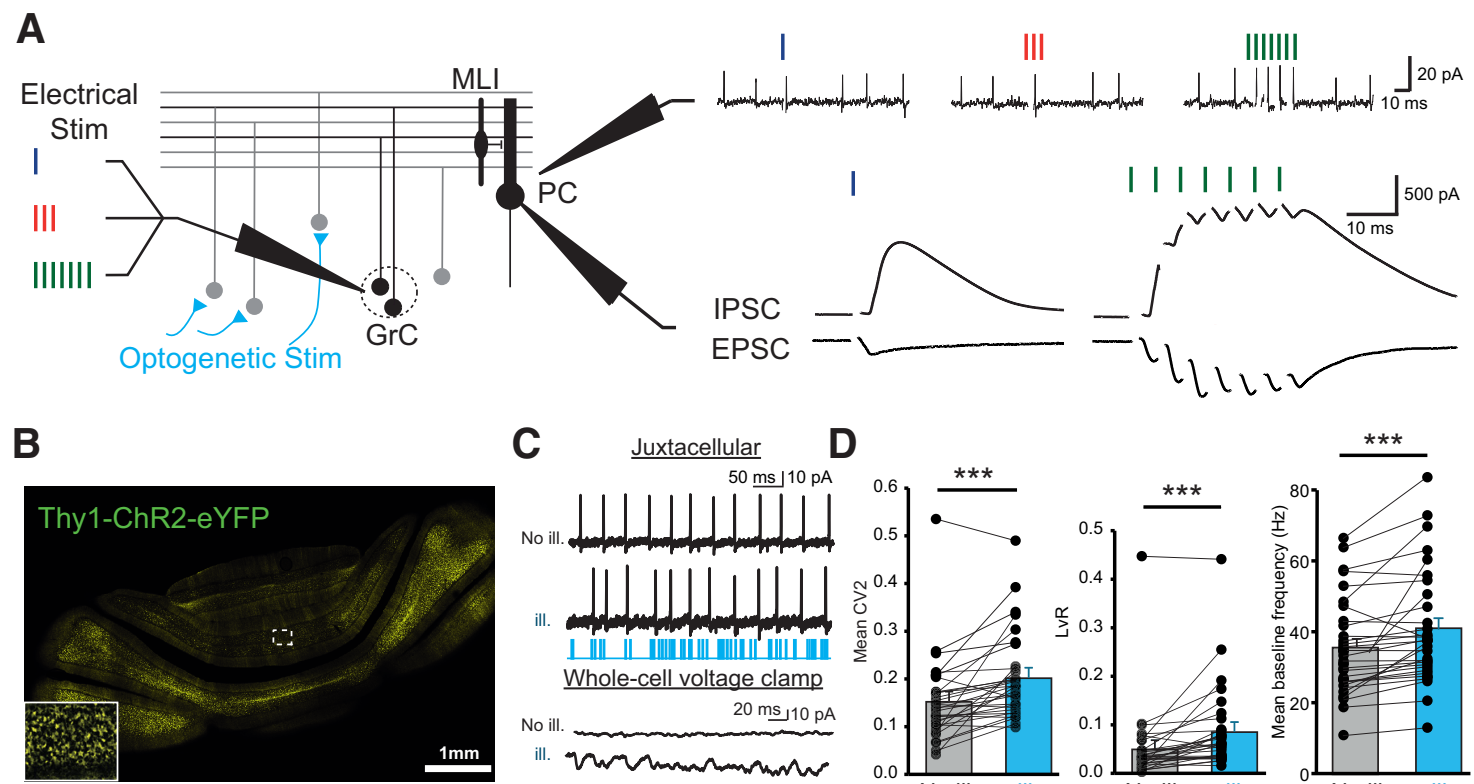

C Juxtacellular D
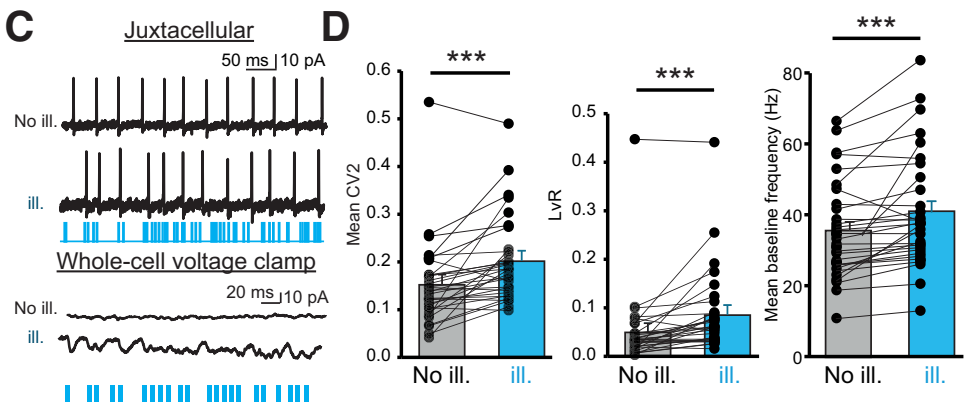

E

Biphasic modulation

\section{$\underline{\text { Accelerating }}$}
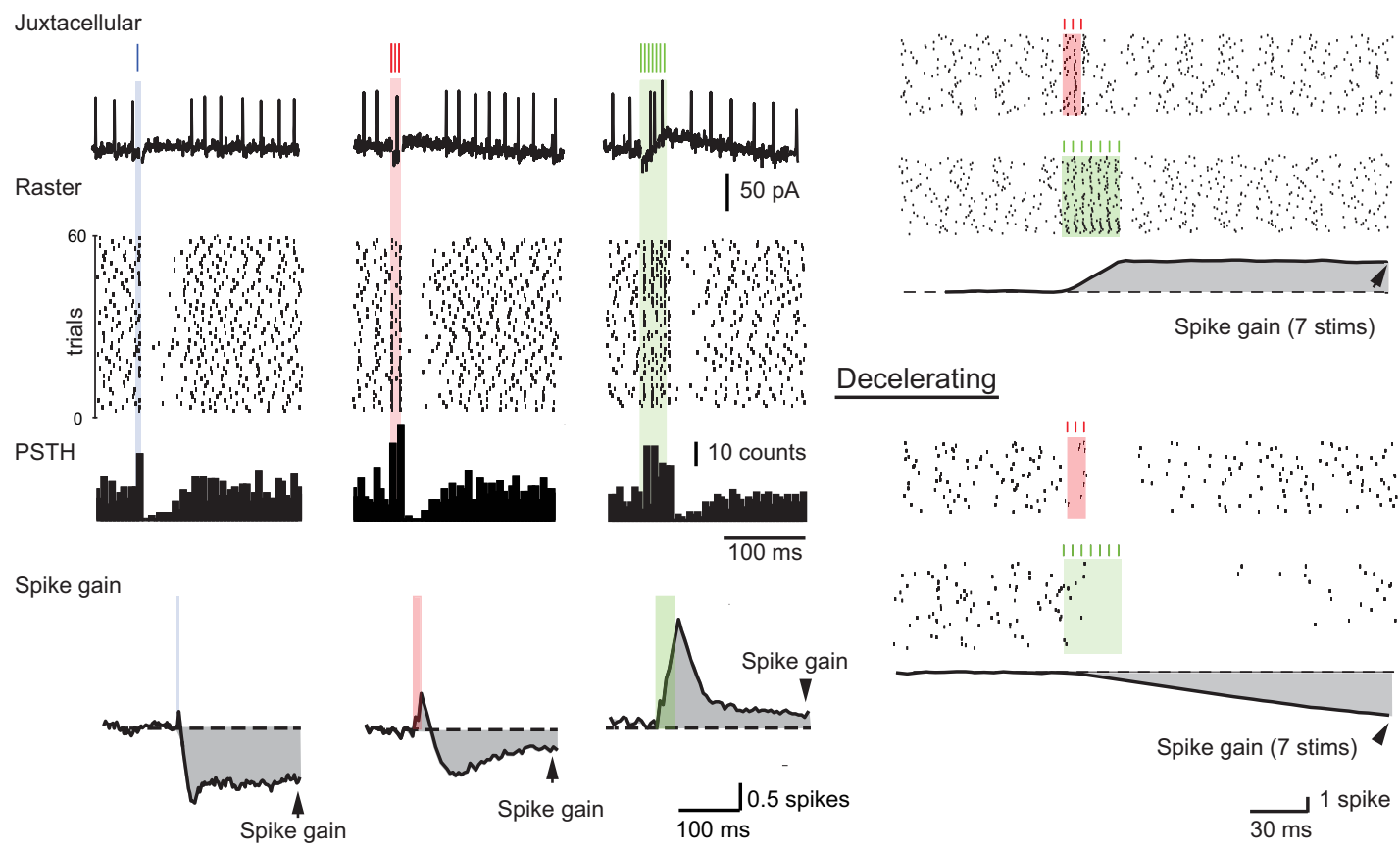

Decelerating
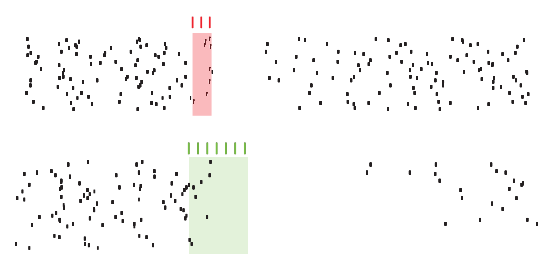

Spike gain (7 stims)

$$
\frac{\mathrm{ms}^{1}}{30 \text { spike }}
$$

Figure 1. Bidirectional influence of $\mathrm{PC}$ discharges by short GrC burst stimuli. A, Left, Diagram of the feedforward inhibitory circuit in the cerebellar cortex. GrCs were stimulated 1, 3, and 7 times during irregular activation of many ChR2-expressing MFs by blue light illumination (optogenetic stim). PCs were first recorded in juxtacellular mode to monitor discharge (top right), then whole-cell patch-clamped to measure synaptic weights and E/I balance (bottom right). Excitation was recorded at $V_{\mathrm{m}}=-60 \mathrm{mV}$, inhibition at $V_{\mathrm{m}}=0 \mathrm{mV}$. $\boldsymbol{B}$, Confocal image of a transverse cerebellar section of a Thy1-ChR2-eYFP adult mouse showing strong eYFP fluorescence in MF rosettes. C, Top, PCs were recorded in juxtacellular, then whole-cell patch-clamped (bottom traces) before and during MF photostimulation (No ill and ill, respectively). Irregular firing and an increase in excitatory and inhibitory synaptic noise were observed. D, Quantitative analyses of PC discharge irregularities. The CV2, the frequency-independent LvR parameter, and the mean baseline frequency significantly increased during MF photostimulation (see Materials and Methods) ${ }^{* * *} p<0.001$, see text. Error bars indicate SEM. E, Left, Example of a biphasic modulation of PC discharge by GrC stimulation and determination of the spike gain. From the raster plots, a mean PSTH was determined and the baseline was subtracted. The spike gain was estimated by integrating this subtracted mean PSTH. Right, Two opposite examples of modulation of PC discharge by GrC stimulations.

$$
\begin{gathered}
\frac{d z_{a}}{d t}=\frac{y_{a}}{\tau_{I}}-\frac{z_{a}}{\tau_{r e c}} \\
\frac{d u_{a}}{d t}=-\frac{u_{a}}{\tau_{f a c i l}}+U_{a}\left(1-u_{a}\right) \delta\left(t-t^{s p i k e}\right)
\end{gathered}
$$

where $x_{a}, y_{a}$, and $z_{a}(a \in\{$ exc., inh. $\})$ are the three state variables that describe the state-dependent use of the synaptic resources in the recovered $\left(x_{a}\right)$, active $\left(y_{a}\right)$, and inactive $\left(z_{a}\right)$ states, respectively. $t^{\text {spike }}$ is the timing of the previous spike. $\tau_{I}$ is the decay time constant of the postsynaptic current, $\tau_{r e c}$ is the time it takes the synaptic resources to recover from their inactive state. The variable $u_{a}(t)$ keeps track of the use of the 

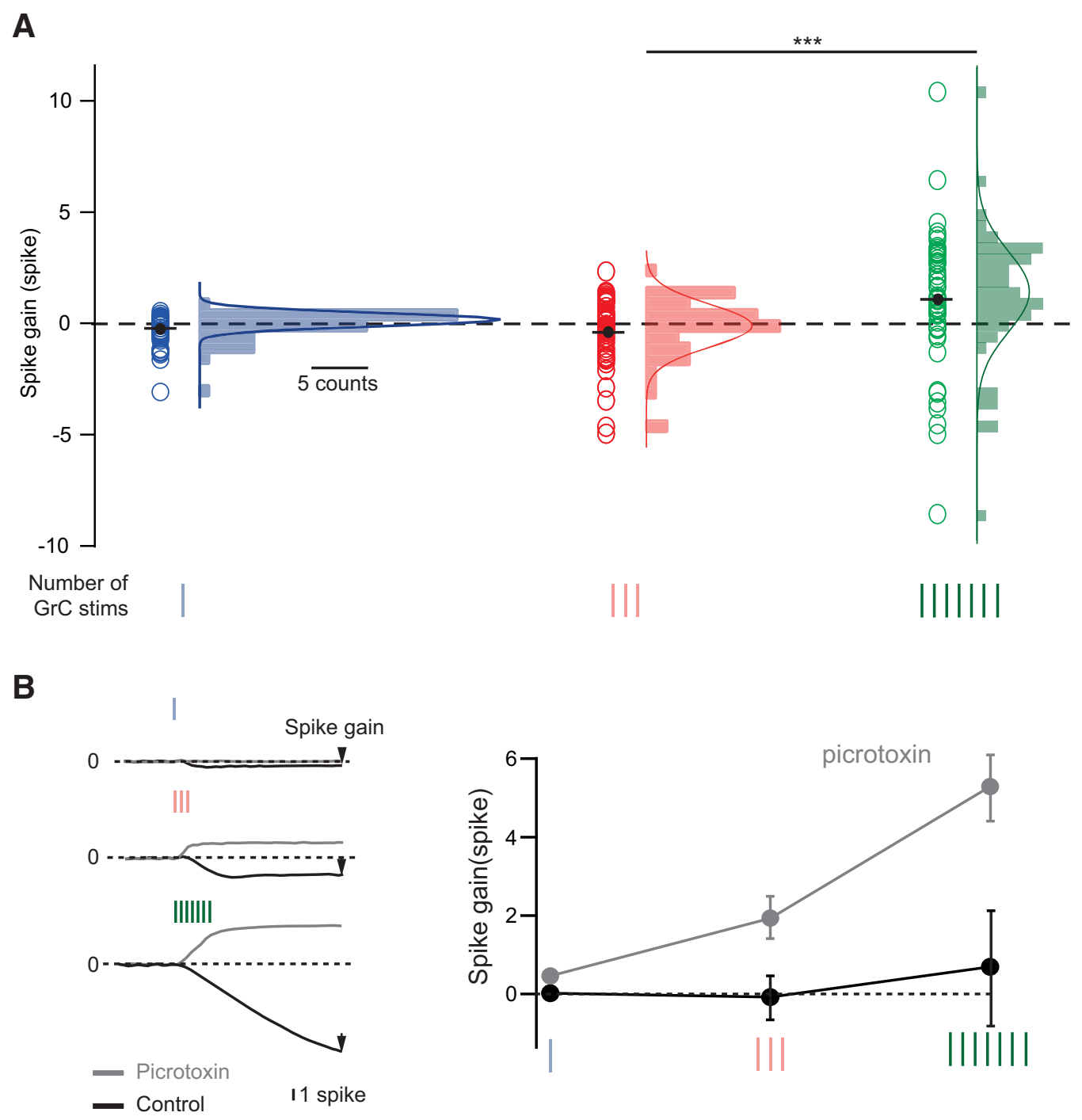

Figure 2. $\operatorname{GrC}$ stimulation can evoke a wide range of PC spike gains. $A$, Spike gain distribution in $\mathrm{PCS}(n=51)$ in response to 1 (blue), 3 (red), or 7 (green) $\operatorname{GrC}$ stimulations at $200 \mathrm{~Hz}$. ${ }^{* * *} p \leq 0.001$ Wilcoxon rank test. $\boldsymbol{B}$, Pauses and decreases in firing rate in $\mathrm{PC}$ discharge are mediated by FFI. Left, Example of a PC showing a negative spike gain in response to 1, 3, or 7 stimulations of GrCs in control condition (black traces) and a positive spike gain in picrotoxin condition (100 $\mu \mathrm{m}$; gray thick traces). Right, Averaged effect of picrotoxin application on spike gain ( $n=7)$. Error bars indicate SEM.

synaptic resources at a synapse. To model synaptic facilitation, the variable $u_{a}$ is instantaneously increased by a small amount of $U_{a}$ at the time of spike and then returns to the baseline value with a time constant $\tau_{\text {facil }}$ (Eq. 7).

The effective synaptic weight was given by the following:

$$
J_{a}(t)=A_{a} \times y_{a}(t)
$$

To systematically change the nature of the synapses from facilitating to depressing, we changed the variable $U_{a}$ while keeping all other variables unchanged. Because we kept all the time constants unchanged in the model, going from facilitation to depression did not affect the frequency dependence of the synapses. The parameter $A_{a}$ was changed to increase the amplitude of the postsynaptic potential independent of the STD. The values of these various parameters are provided in Table 2, and corresponding facilitation and depression of synaptic strength are shown in Figure 4.

Patterned stimulation. The activity of the GrCs was modeled as a train of 3 or 7 spikes (ISI $=5 \mathrm{~ms}$ ) mimicking $\mathrm{GrC}$ stimulation in acute slices. The feedforward inhibition created by the inhibitory interneurons was also modeled as a train of 3 or 7 spikes (ISI $=5 \mathrm{~ms}$ ). Both spike trains were identical in each trial. The inhibitory spikes arrived at the PC $1.5 \mathrm{~ms}$ after the arrival of the excitatory spikes. The excitatory and inhibitory synapses exhibited STD.

All simulations were performed using the NEural Simulation Tool (RRID:SCR_002963) environment (http://www.nest-simulator.org/).

\section{Statistical tests}

Statistical analysis was performed using Sigmaplot software (version 12.0, Systat Software; RRID:SCR_003210) and Igor version 6.12A (Wavemetrics; RRID:SCR_000325). All data are presented as mean \pm SD in the text and SEM on graphs. Statistical tests were specified in the text.

\section{Results}

\section{$\mathrm{GrC}$ stimulations induce a wide range of $\mathrm{PC}$ responses}

We studied how E/I balance and STD of excitatory and inhibitory synapses interact to affect PC discharge, in acute cerebellar slices. GrC groups were stimulated with 1, 3, or 7 stimulation pulses at $200 \mathrm{~Hz}$ as observed in vivo (Chadderton et al., 2004; Jörntell and Ekerot, 2006; Arenz et al., 2008). PC discharges were monitored using juxtacellular recordings (Figs. $1 A ; n=51$ cells, $N=37$ mice; see Materials and Methods). Some PCs were also recorded 
A

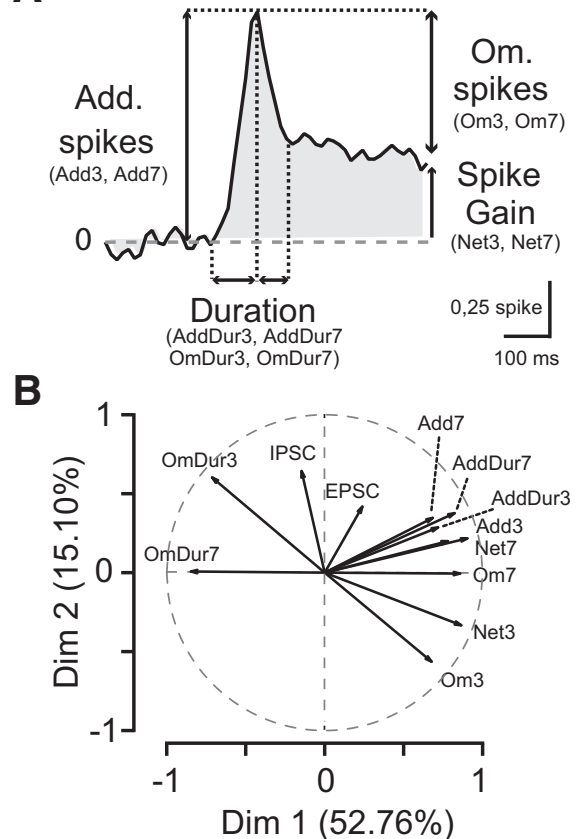

D

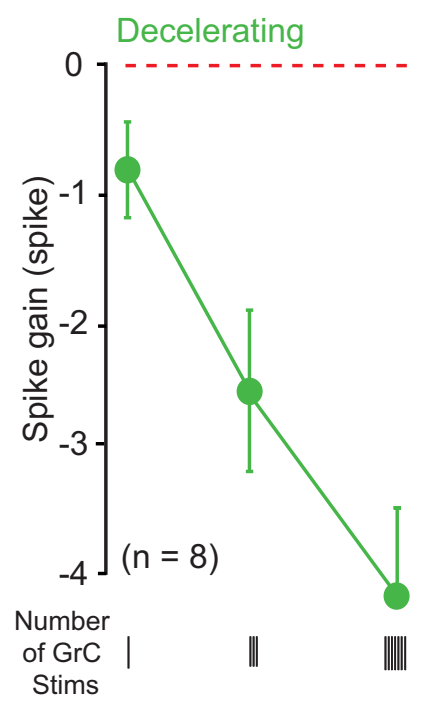

C

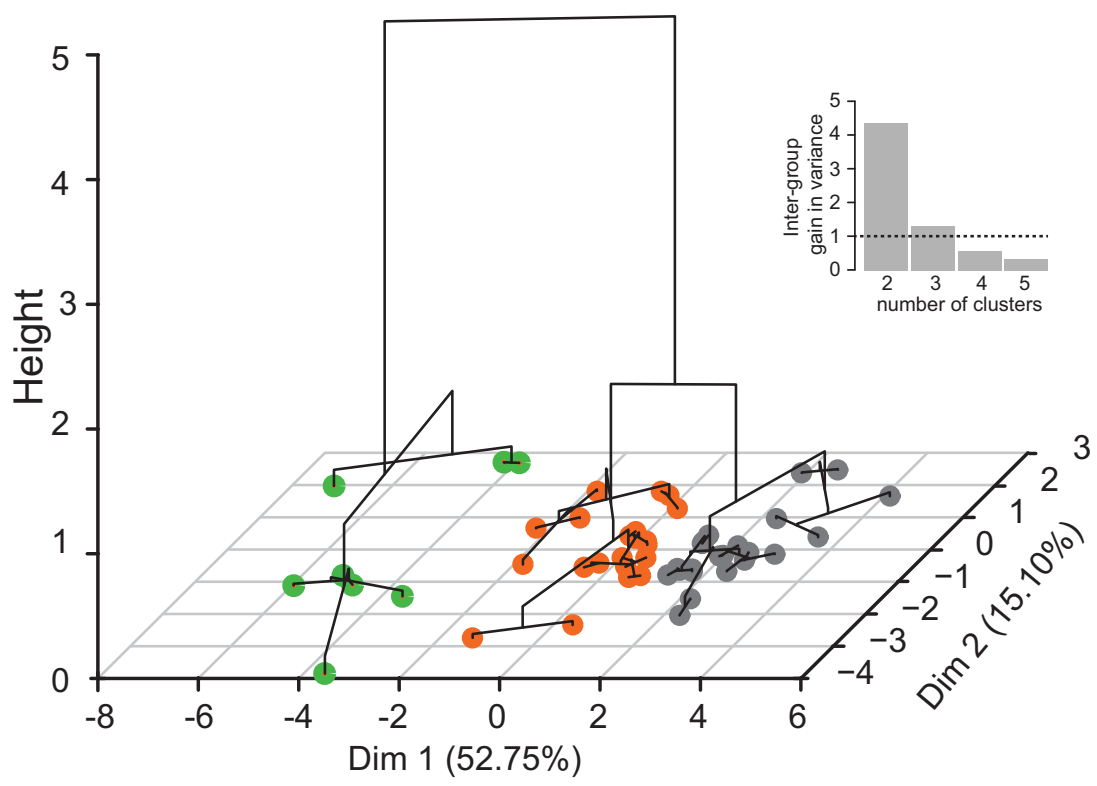

E

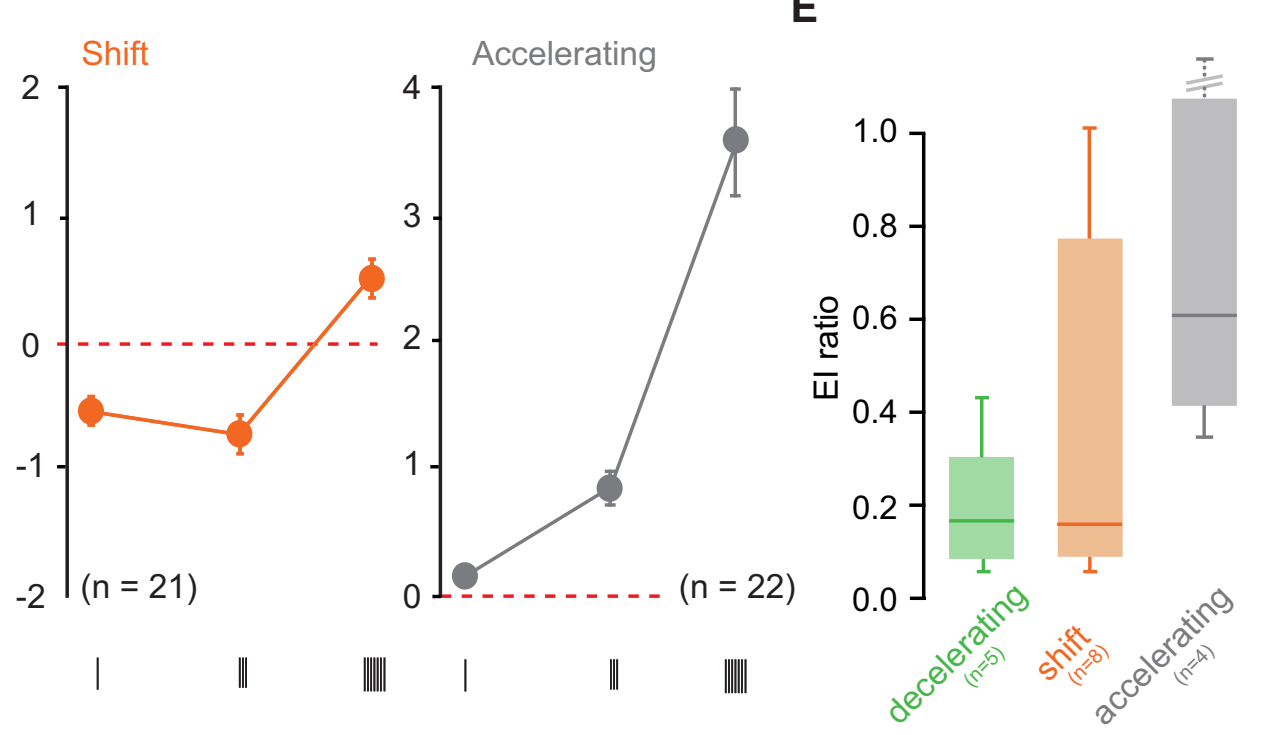

Figure 3. GrC stimulation leads to three identifiable patterns of $\mathrm{PC}$ output. $A-C, P C A$ and hierarchical clustering on principal components on the $51 \mathrm{PC}$ recorded. $A$, Description of the variables used for PCA: Add spikes, Additional spikes (variables: Add3 and Add7, additional spikes for 3 and 7 stimuli); $0 \mathrm{~m}$. spikes, omitted spikes (variables: $0 \mathrm{~m} 3$ and $0 \mathrm{~m} 7$, omitted spikes for 3 and 7 stimuli); Duration, duration of the acceleration and deceleration phases (variables: AddDur 3 and AddDur7, duration of the acceleration phase for 3 and 7 stimuli); $0 \mathrm{mDur} 3$ and OmDur7, duration of the deceleration phase for 3 and 7 stimuli; spike gain (variables: Net 3 and Net7, spike gain for 3 and 7 stimuli). $\boldsymbol{B}$, Polar plot showing the respective contributions of the variables to the $P($ discharge. Projections on $x$ and $y$ axes give the coefficient of correlation between the variable and the two first dimensions of the PCA. C, Projection on the two first principal component dimensions (Dim 1, Dim 2) of the dendrogram distance tree obtained from the hierarchical cluster analysis. Height axis corresponds to the increase in between-group variance. Three groups have been identified ( $n=51$ cells). Inset, Interclass variance as a function of the number of clusters. Straight line indicates the variance below which an additional cluster does not bring a significant variance. Three clusters explain most of the variability. D, Averaged spike gain at 1, 3, and $7 \mathrm{GrC}$ stimuli for each identified group: decelerating (green), shift (orange), and accelerating (gray). Error bars indicate SEM. E, Box plot (min, 25\%, median, 75\%, max) of the E/I ratio per group ( $n=17$ cells). There is scattering in the shift group.

in the whole-cell mode $(n=17$ of $51, N=15$ of 37 ; Fig. $1 A$; see Materials and Methods) to measure EPSCs/IPSCs elicited by GrC stimulations.

In an in vitro preparation, the background synaptic noise is artificially low (Häusser and Clark, 1997; Destexhe et al., 2003; Blot et al., 2016), which led to an overestimation of the influence of evoked synaptic inputs on PC discharge. To overcome this limitation, we used a transgenic mouse expressing Channelrhodopsin2 in MFs (Thy1-ChR2-eYFP; Fig. 1B) in which background activity can be generated by an illumination of blue light. To mimic the variability of PC discharges observed in vivo (Shin et al., 2007; Jelitai et al., 2016), we illuminated the cerebellar slices from Thy1-ChR2-YFP mice in an irregular manner to increase the level of spontaneous EPSCs/IPSCs in PCs (Fig. $1 B-D$; see 
Table 1. Summary of PC responses to $\mathrm{GrC}$ stimulations ${ }^{a}$

\begin{tabular}{|c|c|c|c|c|c|c|c|c|c|c|c|c|c|c|c|c|c|c|}
\hline & \multirow[b]{2}{*}{$\begin{array}{l}\text { EPSC } \\
(\mathrm{pA})\end{array}$} & \multirow[b]{2}{*}{$\begin{array}{l}\text { IPSC } \\
(\mathrm{pA})\end{array}$} & \multirow[b]{2}{*}{$E / I$} & \multicolumn{5}{|c|}{ One stimulation } & \multicolumn{5}{|c|}{ Three stimulation } & \multicolumn{5}{|c|}{ Seven stimulation } \\
\hline & & & & $\begin{array}{l}\text { Add } \\
\text { (sp) }\end{array}$ & $\begin{array}{l}\text { AddDur } \\
\text { (ms) }\end{array}$ & $\begin{array}{l}0 \mathrm{~m} \\
(\mathrm{sp})\end{array}$ & $\begin{array}{l}\text { OmDur } \\
\text { (ms) }\end{array}$ & $\begin{array}{l}\text { Spike } \\
\text { gain } \\
\text { (sp) }\end{array}$ & Add & AddDur & $0 \mathrm{~m}$ & OmDur & $\begin{array}{l}\text { Spike } \\
\text { gain }\end{array}$ & Add & AddDur & $0 \mathrm{~m}$ & OmDur & $\begin{array}{l}\text { Spike } \\
\text { gain }\end{array}$ \\
\hline \multicolumn{19}{|c|}{ Decelerating group } \\
\hline Minimum & 69 & 166 & 0.06 & 0.00 & 0.00 & -3.09 & 0.00 & -3.09 & 0.00 & 0.00 & -5.05 & 10.00 & -4.97 & 0.00 & 0.00 & -8.58 & 90.00 & -8.58 \\
\hline Maximum & 163 & 2755 & 0.43 & 0.12 & 10.00 & 0.45 & 95.00 & 0.10 & 0.39 & 20.00 & -0.10 & 165.00 & -0.10 & 1.24 & 35.00 & -2.55 & 235.00 & -1.31 \\
\hline Mean & 115 & 1121 & 0.18 & 0.04 & 5.00 & -0.73 & 34.38 & -0.80 & 0.09 & 6.88 & -2.59 & 89.38 & -2.51 & 0.17 & 8.75 & -4.30 & 153.75 & -4.13 \\
\hline SEM & 20 & 469 & 0.06 & 0.06 & 1.90 & 0.40 & 12.50 & 0.38 & 0.05 & 2.80 & 0.65 & 19.75 & 0.62 & 0.15 & 5.07 & 0.67 & 21.22 & 0.74 \\
\hline \multicolumn{19}{|l|}{ Shift group } \\
\hline Minimum & 55 & 54 & 0.05 & 0.00 & 0.00 & -1.84 & 0.00 & -1.64 & -0.05 & 5.00 & -2.56 & 10.00 & -2.10 & 0.01 & 5.00 & -1.99 & 0.00 & -0.68 \\
\hline Maximum & 493 & 3188 & 1.02 & 0.36 & 10.00 & 0.00 & 70.00 & 0.08 & 1.00 & 20.00 & -0.20 & 85.00 & 0.21 & 2.28 & 50.00 & 0.00 & 115.00 & 2.01 \\
\hline Mean & 253 & 1566 & 0.34 & 0.12 & 5.48 & -0.63 & 31.90 & -0.51 & 0.38 & 15.71 & -1.06 & 44.29 & -0.68 & 1.30 & 36.43 & -0.77 & 38.33 & 0.52 \\
\hline SEM & 62 & 373 & 0.14 & 0.03 & 0.90 & 0.12 & 4.95 & 0.11 & 0.07 & 1.25 & 0.14 & 4.15 & 0.15 & 0.13 & 2.05 & 0.13 & 6.37 & 0.15 \\
\hline \multicolumn{19}{|c|}{ Accelerating group } \\
\hline Minimum & 18 & 0 & 0.37 & 0.01 & 5.00 & -0.78 & 0.00 & -0.36 & 0.32 & 10.00 & -2.59 & 0.00 & -0.27 & 1.20 & 40.00 & -0.91 & 0.00 & 1.20 \\
\hline Maximum & 617 & 1675 & 1.20 & 0.77 & 20.00 & 0.00 & 50.00 & 0.53 & 2.32 & 40.00 & 0.00 & 80.00 & 2.32 & 11.22 & 70.00 & 0.00 & 40.00 & 10.40 \\
\hline Mean & 319 & 474 & 0.69 & 0.28 & 10.23 & -0.16 & 10.68 & 0.12 & 1.14 & 20.68 & -0.42 & 20.00 & 0.78 & 3.58 & 45.00 & -0.14 & 8.64 & 3.44 \\
\hline SEM & 145 & 402 & 0.15 & 0.04 & 0.60 & 0.04 & 2.90 & 0.04 & 0.08 & 1.05 & 0.13 & 4.95 & 0.13 & 0.43 & 1.70 & 0.05 & 2.75 & 0.40 \\
\hline \multirow[t]{2}{*}{$p K-W$ test } & ns & ns & $n s$ & $* * *$ & $* * *$ & * & $* *$ & $* * *$ & *** & $* * *$ & $* * *$ & *** & *** & $* * *$ & $* * *$ & $* * *$ & $* * *$ & $* * *$ \\
\hline & 0.43 & 0.12 & 0.1 & 4.01e-05 & $3.41 e-04$ & 0.014 & 0.009 & 3.77e-07 & $9.25 \mathrm{e}-12$ & $3.17 e-06$ & $7.48 \mathrm{e}-06$ & $9.55 \mathrm{e}-06$ & $2.10 \mathrm{e}-12$ & $5.34 \mathrm{e}-13$ & $1.92 \mathrm{e}-09$ & $1.19 \mathrm{e}-10$ & 3.1e-09 & 0 \\
\hline
\end{tabular}

${ }^{a}$ Add, Average number of additional spikes; AddDur, average duration of acceleration; $0 \mathrm{~m}$, number of omitted spikes; $0 \mathrm{mDur}$, average duration of deceleration.

${ }^{*} p<0.05 ;{ }^{* *} p<0.01 ;{ }^{* * *} p<0.001 ; \mathrm{K}-\mathrm{W}$ test, Kruskal-Wallis between the three $\mathrm{PC}$ groups (decelerating, shift and accelerating).

Materials and Methods). We adjusted the photostimulation parameters to obtain in vivo-like PC discharges (Fig. $1 C, D$; mean CV2 during illumination: $0.202 \pm 0.09$; control: $0.152 \pm 0.09$, $p=0.001$; mean LvR during illumination: $0.086 \pm 0.084$; control: $0.050 \pm 0.077, p<0.001$; mean baseline frequency during illumination: $40.1 \pm 2.9 \mathrm{~Hz}$; control: $35.1 \pm 2.4 \mathrm{~Hz}, p=0.0006$; Wilcoxon signed rank test, $n=32$ ). To mimic the stimulusinduced activity in vivo, in addition to this background activity, small groups of GrCs were repeatedly stimulated (min 30 trials per protocol), which changed the PC membrane potential (2-3 $\mathrm{mV}$ ) (Jelitai et al., 2016) and the firing rate (Bower and Woolston, 1983; Jaeger and Bower, 1994; Wilms and Häusser, 2015). The mean amplitude of the direct EPSC elicited by a single stimulation of a group of GrCs was $228 \pm 190 \mathrm{pA}$ (at $-60 \mathrm{mV} ; n=17$ ) and the mean disynaptic IPSC was $1178 \pm 1040 \mathrm{pA}$ (at $0 \mathrm{mV} ; n=$ 17). This suggests that the number of nonsilent $\mathrm{GrC}$ synapses in the stimulated groups was between 5 and 50 (Isope and Barbour, 2002; Schmidt et al., 2013). The mean latency between EPSC and IPSC was $1.91 \pm 0.46 \mathrm{~ms}(n=18)$ in agreement with previous observations (Brunel et al., 2004; Mittmann and Häusser, 2007).

To quantify the net increase (or decrease) in the PC firing rate in response to the $\mathrm{GrC}$ stimulations, we defined the "spike gain." The spike gain was calculated by integrating the mean PSTH of the PC spike train after baseline subtraction (Fig. 1E; see Materials and Methods) (Mittmann and Häusser, 2007). An increase (or decrease) in spike gain after the stimulus onset corresponds to a net increase (or decrease) in the firing rate. If $\mathrm{PC}$ discharge is controlled solely by the overall E/I balance, we expect that increasing the number of stimuli will only affect the magnitude of the spike gain. However, if excitatory and inhibitory synapses also exhibit STD, the sign of the spike gain may also be inverted when the number of GrC stimuli is increased. In 40 of the 51 recorded PCs, GrC stimulations elicited biphasic changes in firing rate, illustrating the E/I sequence characteristic of the FFI motif (Fig. $1 E)$. The spike gain was found to be highly variable across PCs, from -3.09 to 0.53 spike on average for a single stimulation. This indicates that even a single stimulation of a group of $\mathrm{GrCs}$ can drive an overall increase (acceleration $n=21$ ) or decrease (de- celeration $n=27$ ) in the PC discharge rate (Figs. $1 E, 2 A$, blue circles). Increasing the duration of the $\mathrm{GrC}$ stimulation ( 3 and 7 pulses at $200 \mathrm{~Hz}$ ) further increased the variability of the spike gain (Fig. 2A) and significantly skewed the distribution toward a positive spike gain $($ mean $=-0.34 \pm 1.46$ and $1.05 \pm 3$ spike for 3 and 7 stimuli, respectively; Wilcoxon signed rank test, $p=2.3 \times$ $10^{-6}$ ). PC discharge could be accelerated up to $138 \pm 37 \mathrm{~Hz}$ (for 7 stimulations) or silenced (mean pause duration for 7 stimuli $=$ $123 \pm 64 \mathrm{~ms}, n=13$ of 51 ). To confirm that the negative part of the spike gain was mediated by the FFI, we blocked inhibition by the application of picrotoxin $(100 \mu \mathrm{M}), \mathrm{GABA}_{\mathrm{A}}$ receptor antagonist. This led to a positive spike gain for all the cells $(n=7$; Fig. $2 B$; mean spike gain 1 stim, control $=0.02 \pm 0.11$ spike, picrotoxin $=0.46 \pm 0.08$ spike, $p=0.015 ; 3$ stims, control $=-0.08 \pm$ 0.42 spike, picrotoxin $=1.93 \pm 0.4$ spike, $p=0.016 ; 7$ stims, control $=0.69 \pm 1.62$ spike, picrotoxin $=5.29 \pm 1.04$ spike, $p=$ 0.016; Wilcoxon signed rank test).

\section{Burst duration influences the sign of the spike gain}

To classify the wide range of PC responses to GrC stimulations, we used PCA (Fig. $3 A-C$ ). We chose 10 parameters describing the PC spike train statistics for 3 and 7 stimuli and the evoked synaptic weights (EPSC and IPSC) for 1 stimulus (Fig. 3A; see Materials and Methods). The number of omitted spikes for 7 stimuli (Om7), the duration of PC inhibition for 7 stimuli (OmDur7; determined by the FFI), and the duration of the stimulus (Net7, Net3: the spike gain elicited by 3 and 7 GrC stimuli) emerged as key parameters (correlation coefficient $>0.8$ with Dim 1 ; Fig. $3 B$ ) that classified different PC responses. EPSC and IPSC amplitudes were correlated only with the second dimension of the PCA (correlation coefficient ${ }_{E P S C}=0.42$, correlation coefficient IPSC $_{I P A}=0.64$ with Dim 2, Fig. $3 B$ ). Because they explain the majority of the variance (dimension 1, 52.76\%; dimension 2, 15.1\%), the first two dimensions of the PCA were used in a hierarchical clustering method, which identified three groups of PC responses (Fig. $3 C$ ).

The first two groups were characterized by a monotonic increase or decrease in spike gain as the stimulus duration was increased. We refer to these as accelerating $(n=22$ of 51 cells, $43.1 \%)$ and decelerating ( $n=8$ of 51 cells, $15.7 \%$ ) groups (Fig. $3 D$ ). Cells in 
A

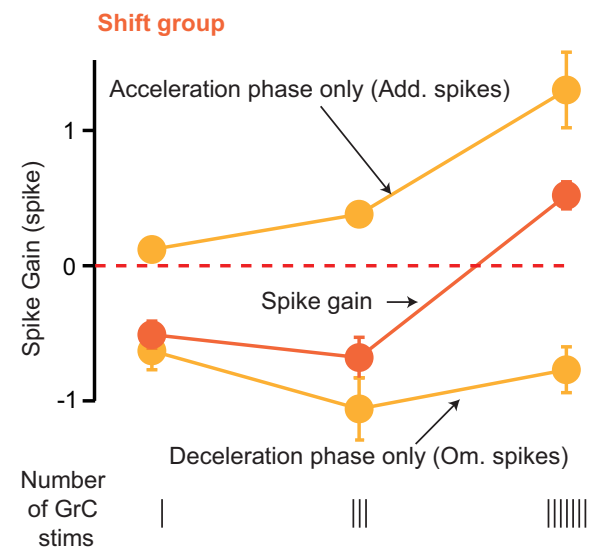

B

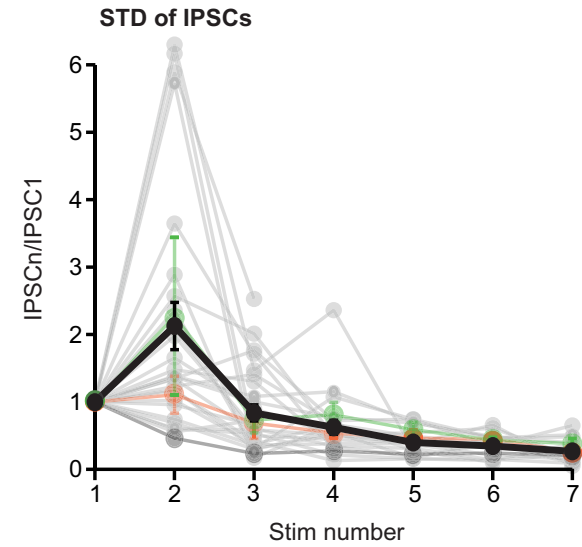

STD of EPSCs

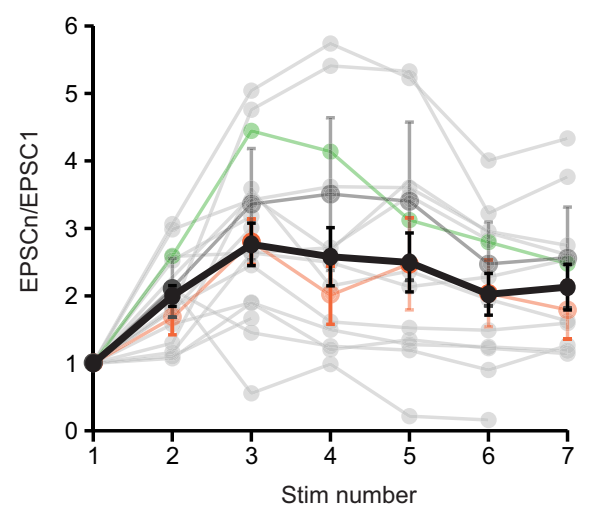

Figure 4. E/I ratio is strongly affected by STD. $\boldsymbol{A}$, Evolution of the net spike number in the shift group for 1, 3, and $7 \mathrm{GrC}$ stimuli. Top, Acceleration phase (Add spikes phase only). Middle, Spike gain. Bottom, Deceleration phase (0m spikes phase only). Error bars indicate SEM. B, STD of excitation and inhibition at each stimulus number in a train (1-7 stimuli) of $\mathrm{GrC}$ stimuli at 200 $\mathrm{Hz}$. STD are determined by the ratio $\mathrm{PSC}_{n} / \mathrm{PSC}_{1}$. Gray traces represent all individual cells. Colored traces represent averaged data per group: mean \pm SEM (when $n>1$ ) for shift (orange), decelerating (green), and accelerating groups (dark gray) for cells recorded both in juxtacellular and in whole-cell mode. Black represents overall mean \pm SEM.

these two groups predominantly received either excitation or inhibition (median E/I accelerating $=0.6, n=4$; median $\mathrm{E} / \mathrm{I}$ decelerating $=0.18, n=5$; Fig. $3 E$; Table 1 ). The monotonic change in the PC spike gain for longer stimulation can be attributed to temporal summation of incoming inputs.
Table 2. Model parameters

\begin{tabular}{|c|c|}
\hline Parameter & Value \\
\hline \multicolumn{2}{|l|}{ Neuron parameters } \\
\hline Membrane capacitance $\left(C_{m}\right)$ & $250 \mathrm{pF}$ \\
\hline Membrane time constant $\left(\tau_{\mathrm{m}}\right)$ & $20 \mathrm{~ms}$ \\
\hline Resting membrane potential $\left(\mathrm{V}_{\text {rest }}\right)$ & $-70 \mathrm{mV}$ \\
\hline Refractory period $\left(\tau_{\text {ref }}\right)$ & $2 \mathrm{~ms}$ \\
\hline Spike threshold $\left(\mathrm{V}_{\text {th }}\right)$ & $-55 \mathrm{mV}$ \\
\hline \multicolumn{2}{|l|}{ Excitatory synapse properties } \\
\hline Excitatory reversal potential & $0 \mathrm{mV}$ \\
\hline Excitatory time constant & $1 \mathrm{~ms}$ \\
\hline Static unitary EPSP & $0.5-4 \mathrm{mV} @-70 \mathrm{mV}$ \\
\hline Synaptic delay & $1 \mathrm{~ms}$ \\
\hline \multicolumn{2}{|l|}{ Short-term dynamics of excitatory synapses } \\
\hline Synaptic decay time constant $\left(\tau_{p s c}^{\text {exc }}\right)$ & $1.5 \mathrm{~ms}$ \\
\hline Recovery time constant $\left(\tau_{r e c}^{e x c}\right)$ & $30 \mathrm{~ms}$ \\
\hline Facilitation time constant $\left(\tau_{f a c}^{e x c}\right)$ & $500 \mathrm{~ms}$ \\
\hline Fraction of opened calcium channels ( $\left.U^{e x c}\right)$ & $0.02-0.5$ \\
\hline Synaptic amplitude scaling $\left(A^{e x c}\right)$ & 1.5-337.5 (EPSP range: $0.5-4 \mathrm{mV}$ ) \\
\hline \multicolumn{2}{|l|}{ Inhibitory synapse properties } \\
\hline Inhibitory reversal potential & $-80 \mathrm{mV}$ \\
\hline Inhibitory time constant & $5 \mathrm{~ms}$ \\
\hline Static unitary IPSP & -0.3 to $-1.4 \mathrm{mV} @-70 \mathrm{mV}$ \\
\hline Synaptic delay & $2.5 \mathrm{~ms}$ \\
\hline \multicolumn{2}{|l|}{ Short-term dynamics of inhibitory synapses } \\
\hline Synaptic decay time constant $\left(\tau_{p s c}^{i n h}\right)$ & $1.5 \mathrm{~ms}$ \\
\hline Recovery time constant $\left(\tau_{p s c}^{i n h}\right)$ & $100 \mathrm{~ms}$ \\
\hline Facilitation time constant $\left(\tau_{p s c}^{i \text { inh }}\right)$ & $800 \mathrm{~ms}$ \\
\hline Fraction of opened calcium channels $\left(\tau_{p s c}^{i n h}\right)$ & $0.03-06$ \\
\hline Synaptic amplitude scaling $\left(\tau_{p s c}^{i n h}\right)$ & $\begin{array}{c}-1.667 \text { to }-150 \text { (IPSP range: } \\
-0.3 \text { to }-1.4 \mathrm{mV})\end{array}$ \\
\hline
\end{tabular}

The third group ( $n=21$ of 51 cells, $41.1 \%$ ) was characterized by a significant change in the sign of the spike gain when burst duration was increased from 3 to $7 \mathrm{GrC}$ stimuli (mean spike gain for 3 stimuli $=-0.68 \pm 0.7$ spike; 7 stimuli $=0.52 \pm 0.67$ spike, $p=1.9 \times 10^{-6}$; Wilcoxon signed rank test). In this group, the negative spike gain observed for 1 and 3 stimuli was switched to a positive spike gain for 7 stimuli in 17 of 21 cells (Fig. 3D; Table 1). We refer to these neurons as the "shift group." The E/I balance was more variable than observed in the other two groups (mean $\mathrm{EPSC}=253 \pm 176 \mathrm{pA}$, mean IPSC $=1566 \pm 1054 \mathrm{pA} ; n=8$; Fig. $3 E$, orange). In addition, in this group of cells, no correlation was found between either the spike gain and E/I balance (Pearson: $\rho=0.33, p=0.42$ and $\rho=0.26, p=0.53$ for 3 and 7 stimuli, respectively) or between the amplitudes of the first PSCs (IPSC and EPSC $_{1}$; Pearson $\rho=0.24, p=0.55 ; n=8$ ). These analyses show that the initial E/I balance based on postsynaptic synaptic weight is a poor predictor of the influence of $\mathrm{GrC}$ stimulations on PC discharge when burst duration increases, suggesting that presynaptic STD may play a major role.

\section{STD at excitatory and inhibitory synapses account for the shift group}

The fact that spike gain can be negative for bursts of 3 stimuli and positive for 7 stimuli suggests that E/I balance may shift toward more excitation as the stimulation duration increases. Such a change in the $\mathrm{E} / \mathrm{I}$ balance can be attributed to synaptic facilitation and/or depression. Indeed, $>10 \mathrm{~Hz}$, a short-term facilitation (at the GrC-PC synapse) and a short-term depression (at the MLI-PC synapses) have been reported (Atluri and Regehr, 1996; Isope and Barbour, 2002; Bao et al., 2010; Valera et al., 2012). To test this hypothesis, we plotted the magnitude of the acceleration and deceleration phases (see Add spikes and Om spikes, respectively, 

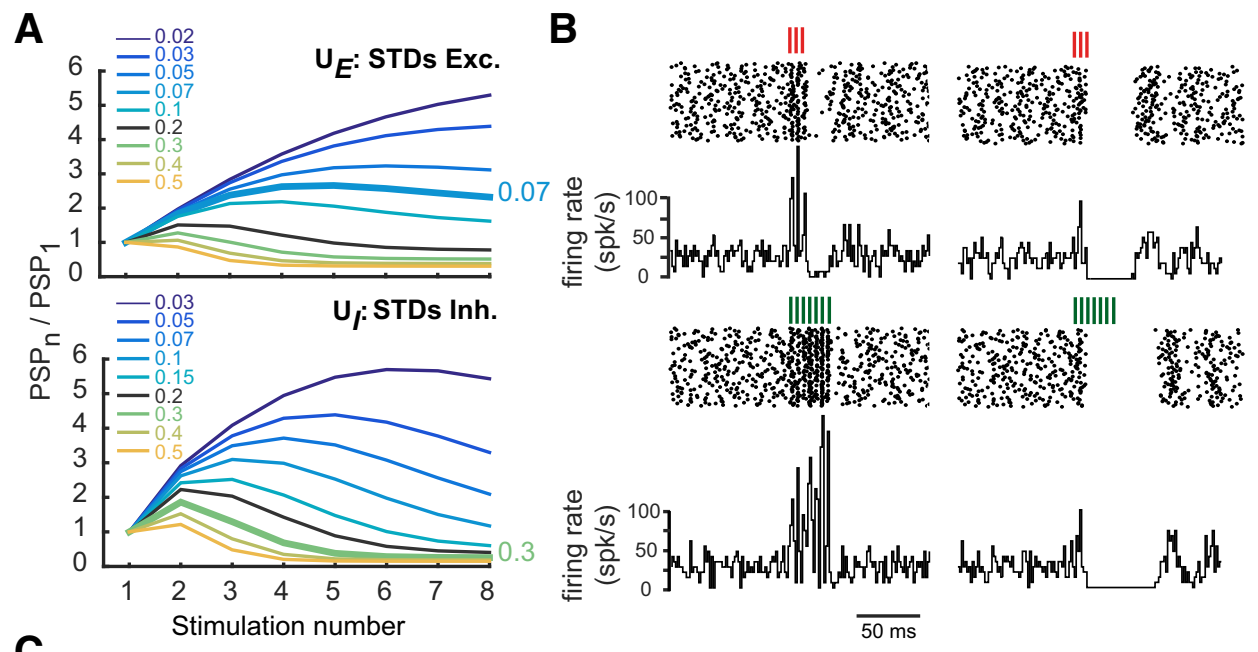

C

Simulation for EPSP $=2.7 \mathrm{mV}$ and IPSP $=-1.2 \mathrm{mV}$
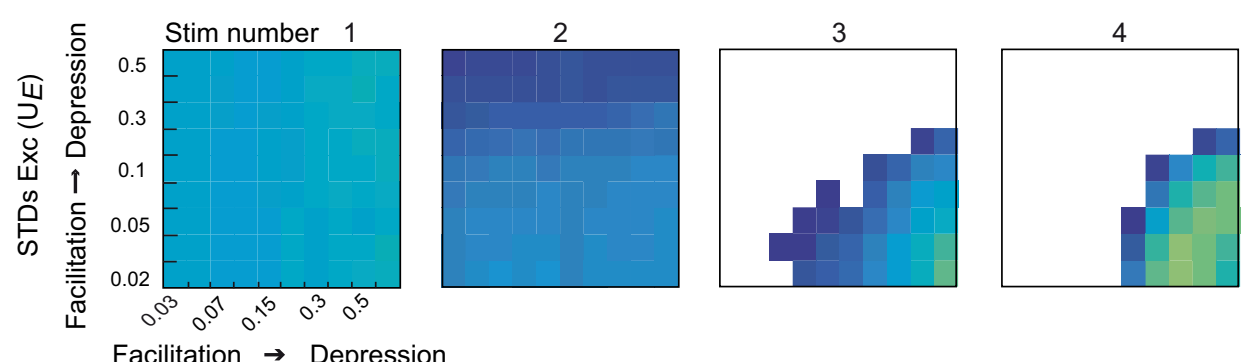

STDs Inh. $\left(U_{l}\right)$
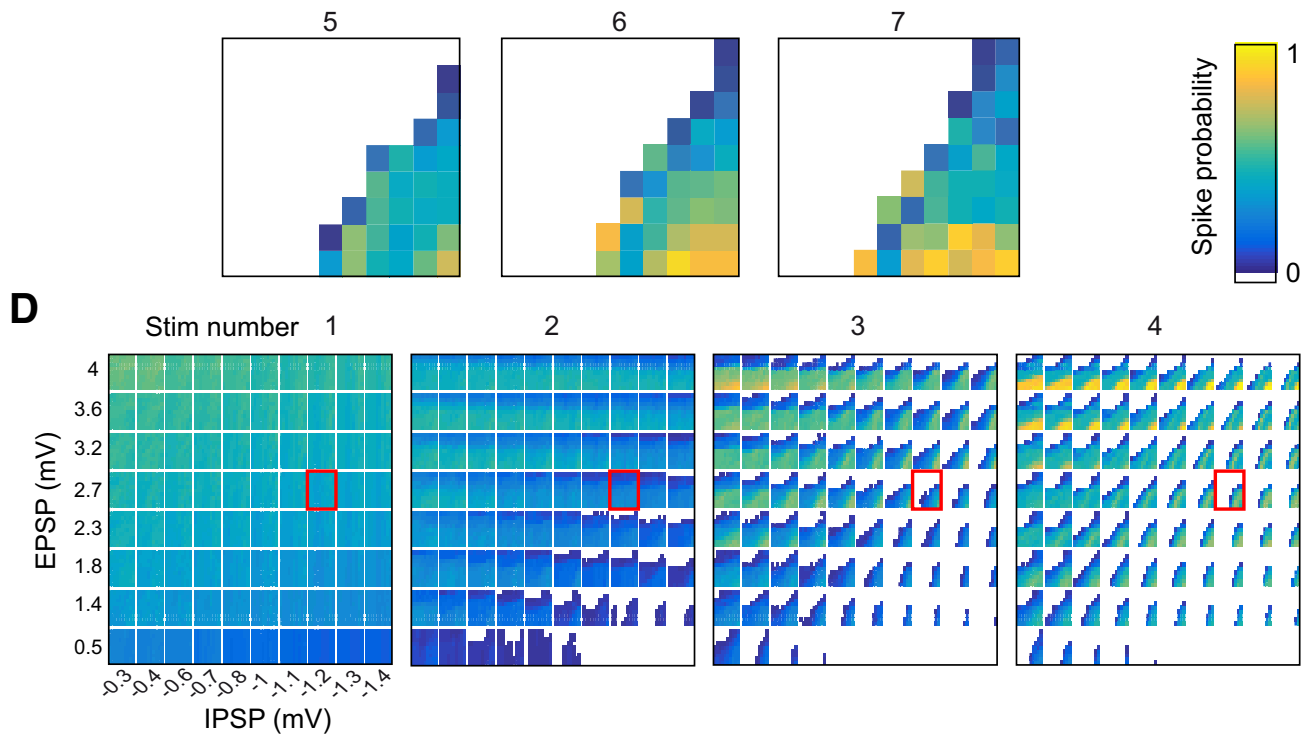

2
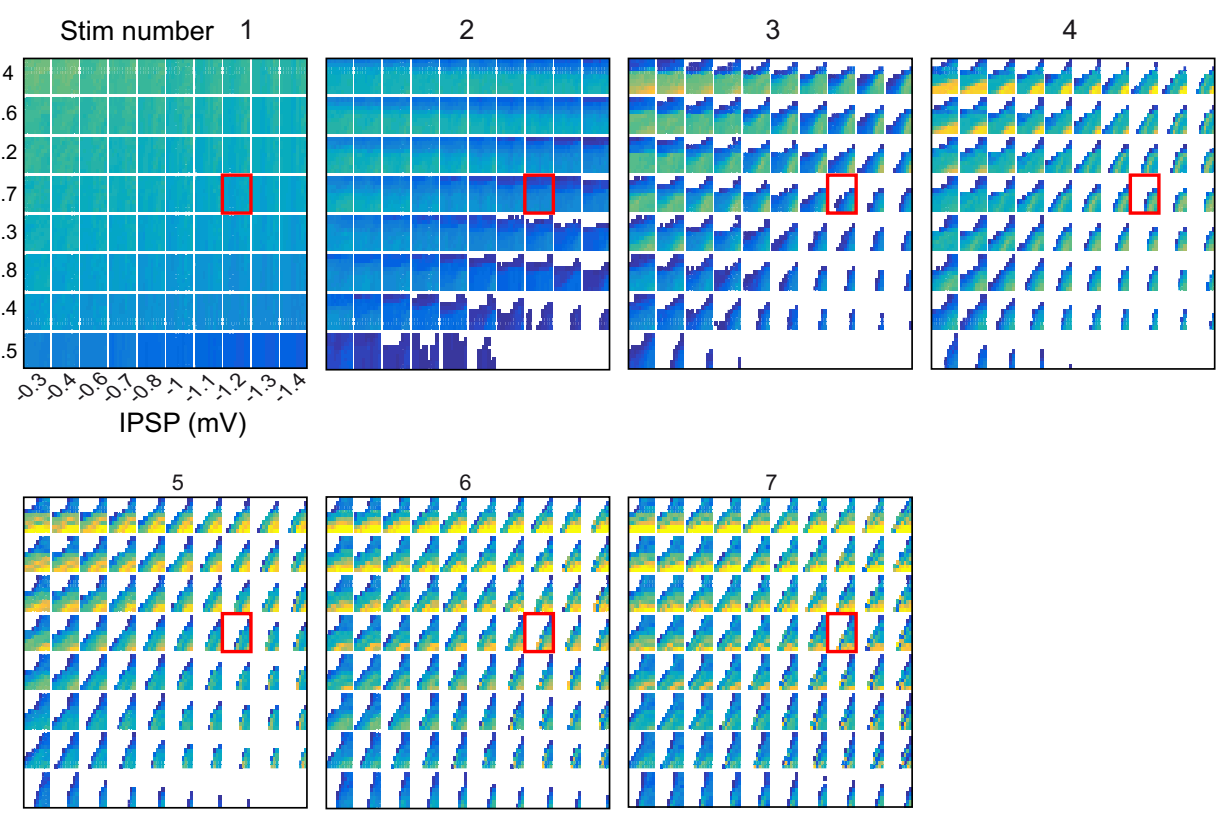

Figure 5. Varying E, I, and STD at the excitatory and inhibitory pathways of a simple model reproduces discharge patterns seen in vitro. $A$, STD of simulated EPSPS (top) and IPSPS (bottom). Ratios $P S P_{n} / P S P_{1}$ were determined for a range of $U$ variables $\left(U_{E}\right.$ and $U$, for excitation and inhibition, respectively; see Materials and Methods). Thicker lines indicate $U_{E}$ and $U_{1}$ values simulating the averaged experimental STD (Fig. 4). B, Examples of simulated raster plots and PSTH. Left, Response of a PC for 3 and $7 \mathrm{GrC}$ stimuli at $200 \mathrm{~Hz}$. Excitation is strong and facilitates, (Figure legend continues.) 
Fig. $4 A$ ) of the PC discharge of the shift group. We found that the deceleration phase was significantly reduced as the number of GrC stimulations was increased from 3 to 7 (Fig. $4 A$; deceleration phase 3 stimuli $=-1.06 \pm 0.6,7$ stimuli $=-0.77 \pm 0.6, p=0.02$ Wilcoxon signed rank test; $n=21)$. Next, we measured the STD of excitatory and inhibitory synaptic inputs (Fig. 4B), which correspond to the monosynaptic GrC-PC and the disynaptic GrCMLI-PC connections, respectively. EPSC (IPSC) amplitudes were normalized to the first EPSC at each position in a burst (ratio PSCn/PSC 1 with $n=1-7$ ) in two sets of experiments. In a subset of the experiments, the PCs were recorded both in juxtacellular and whole-cell mode and STD measurements have been performed ( $n=12 ; 6$ shift, 3 decelerating and 3 accelerating PCs). In addition, 16 PCs were recorded only in the whole-cell mode to measure STD ( $n=16$; see Materials and Methods). On average, at $200 \mathrm{~Hz}$, excitation facilitated during the burst (EPSC $/$ $\mathrm{EPSC}_{1}=2 \pm 0.62, n=17 ; \mathrm{EPSC}_{7} / \mathrm{EPSC}_{1}=2.68 \pm 1.46, n=13$; Fig. $4 B$, STD excitation, black thick line), whereas inhibition facilitated at the second stimulation $\left(\mathrm{IPSC}_{2} / \mathrm{IPSC}_{1}=2.12 \pm 1.82\right.$, $n=27$ ) but strongly depressed thereafter $\left(\right.$ IPSC $_{7} /$ IPSC $_{1}=0.27 \pm$ $0.18, n=15$; Fig. $4 B$, STD inhibition, black thick line), yielding a severalfold increase in the dynamic E/I ratio. In the shift group, the E/I ratio increased between 3 and 7 stimuli (median E/I ratio $1 \mathrm{stim}=0.15,3 \mathrm{stim}=1.24,7 \mathrm{stim}=5.51)$. However, STD were spread across PC groups (Fig. $4 B$, orange, green, and dark gray lines), and no correlation between STD and PC groups was observed (e.g., for 7 stimuli mean $\mathrm{EPSC}_{7} / \mathrm{EPSC}_{1}$ shift group $=$ $1.79 \pm 1.05$, accelerating group $=2.57 \pm 1.81, p=0.15$, Wilcoxon rank test; mean $\mathrm{IPSC}_{7} / \mathrm{IPSC}_{1}$ shift group $=0.26 \pm$ 0.15 , decelerating group $=0.9 \pm 1.3, p=0.08$, Wilcoxon rank test). These findings suggest that, if an increase in the number of stimulations of a $\mathrm{GrC}$ cluster enhances excitation over inhibition, a complex interplay between STD and E/I balance determines PC discharge.

\section{Interplay of STD and E/I balance determines the heterogeneity of $\mathrm{PC}$ responses}

Next, we tested how E, I, and STD in the GrC-PC and GrC-MLI-PC pathways can explain the diversity of $\mathrm{PC}$ discharge patterns observed in response to GrC stimulation. E/I balance and STD are not independent synaptic parameters because pharmacological agents or calcium concentration that modify STD at the GrC-PC synapses also alter the probability of vesicular release, thereby affecting synaptic strength and E/I balance (Zucker and Regehr, 2002). Therefore, we used a computational model of the GrCMLI-PC feedforward pathway (see Materials and Methods) to understand the interplay between E/I balance and STD and their influence on PC discharge over a wide range of conditions. STD of EPSPs and IPSPs amplitude were simulated using the deter-

\section{$\leftarrow$}

(Figure legend continued.) whereas inhibition is small and depresses mildly (EPSPs $=3.0 \mathrm{mV}$ at $-70 \mathrm{mV}, U_{E}=0.05 ; \mathrm{IPSP}=-0.8 \mathrm{mV}$ at $\left.-70 \mathrm{mV}, U_{I}=0.3\right)$. Right, Simulated PC response for weak depressing excitation and strong facilitating inhibition (EPSPS $=1.2 \mathrm{mV}, U_{E}=0.5$; IPSP $=-1.2 \mathrm{mV}$ at $\left.-70 \mathrm{mV}, U_{I}=0.05\right)$. C, Reproducing $P$ ( response variability by combining E/I balance and STD. Spike probability for a given set of E/I balance (EPSP $=2.7 \mathrm{mV}$ and IPSP $=$ $-1.2 \mathrm{mV}$ ). Inner rectangles in each subpanel represent the spike probability following a given stimulation (5 ms window) as a function of STD. Within each subpanel, EPSPs range from facilitating to depressing from bottom to top, whereas IPSPs go from facilitating to depressing from left to right. $\boldsymbol{D}$, Spike probability following $\mathrm{GrC}$ stimulation (1-7) as a function of EPSP ( $y$ axis) and IPSP ( $x$ axis) amplitudes. Inner rectangles in each subpanel represent the spike probability as a function of STD as in C. Rectangles highlighted in red represent EPSP $=2.7 \mathrm{mV}$ and IPSP $=-1.2 \mathrm{mV}$ expanded in $\mathbf{C}$. ministic model proposed by Tsodyks and Markram (1997) (Table 2) in which a single parameter $(U)$ can be used to systematically change the nature of a synapse from a facilitating to a depressing mode. In this model, a set of four parameters described the E/I balance (EPSP and IPSP amplitudes) and the STD of excitation $\left(U_{E}\right)$ and inhibition $\left(U_{I}\right)$. We systematically varied $U_{E}(0.02-0.5)$ and $U_{I}(0.03-0.6)$ to obtain different degrees of facilitation and depression for $\mathrm{E}$ and I synapses (Fig. $5 \mathrm{~A}$ ). $U_{E} \approx$ 0.07 and $U_{I} \approx 0.3$ corresponded to the average excitatory and inhibitory STD measured in our experiments (biological range: $0.02<U_{E}<0.2$ and $0.15<U_{I}<0.6$ ).

We simulated the evolution of the spike probability for the 3 GrC stimulation protocols (1, 3, and 7 stimuli at $200 \mathrm{~Hz}, 100$ trials per set of parameter) and systematically varied the four model parameters (Fig. $5 B-D$ ). EPSP values ranged between 0.5 and $4 \mathrm{mV}$ at $-70 \mathrm{mV}$. The maximum EPSP value used in the model corresponds to a maximal EPSC of $\sim 500 \mathrm{pA}$ (Isope and Barbour, 2002), the upper bound of our recorded dataset (Table 1). IPSPs (between $-0.3 \mathrm{mV}$ and $-1.4 \mathrm{mV}$ at $-70 \mathrm{mV}$ ) were then constrained by matching the resulting spike output with experimental data (Fig. 5B). An example of the spike probability for every stimulation pulse (1-7) is shown in Figure $5 C$ (extracted from the full simulation displayed in Fig. 5D). As expected, an increase in the EPSP or IPSP amplitude resulted in a corresponding increase or decrease in the probability of the PC to elicit a spike in response to a single stimulation (Fig. $5 D$, see first column or bottom row of the first panel stim number 1 ). In our simulations, we could modulate spike probability of a PC between 0.1 to 0.6 by varying the amplitude of EPSP and IPSP. When excitatory synapses are facilitating $\left(U_{E}<0.2\right.$; see Fig. $\left.5 A\right)$ and inhibitory synapses are depressing $\left(U_{I}>0.15\right.$; Fig. $5 D$, bottom right part of the inside rectangles; Fig. $5 C$, bottom right part of each stimulation panel), the spike probability increased with every stimulation in the input sequence and saturated to 1 . On the other hand, when excitatory synapses are depressing $\left(U_{E}>0.2\right.$, see Fig. $\left.5 D\right)$ and inhibitory synapses are facilitating $\left(U_{I}<0.15\right.$; upper left part of the inside rectangles), spike probability decreased with stimulation number in the input sequence and can be reduced to zero. Thus, spike probability depends on E/I balance, STD of the excitation and inhibition, and the rank of stimulation in the sequence.

After estimating spike probability, we computed the spike gain for a biologically plausible range of $\mathrm{E}, \mathrm{I}$, and STD parameters. We first considered static synapses ( $U_{E}$ and $U_{I}$ not included in the simulation) in which only $\mathrm{E}$ and I varied and compared the sign of the spike gain for the 3 and $7 \mathrm{GrC}$ stimuli. For a wide range of E and I values (Fig. 6A, white circles), we found that the spike gain sign mostly did not depend on the E/I values (Fig. $6 A$, green and gray quarters). For some values of $\mathrm{E} / \mathrm{I}$ synapses, spike gain changed the sign but only from positive to negative (Fig. $6 \mathrm{~A}$, blue region). These results show that neurons with static synapses cannot show shift cell behavior in a biologically realistic range of excitatory and inhibitory synaptic strengths. On the contrary, when synapses exhibited STD, the sign of the spike gain could be reversed (as for the shift group in the experimental dataset) between 3 and 7 stimulation cases for a wide range of E, I, and STD parameters values (Fig. $6 B$, orange region). Moreover, for a given E/I balance, STD can modulate how GrCs influence PC discharge (Fig. 6B, right). For fixed values of EPSP and IPSP, all 3 types of PC responses can be observed by varying the STD parameters. For instance, when EPSP $=2.3 \mathrm{mV}$ and IPSP $=-1 \mathrm{mV}$, by varying the facilitation (at the excitatory synapse) and depression (at the inhibitory synapse), the GrC simulation led to $44 \%$ of accelerating 


\section{A}

\section{Static synapses}

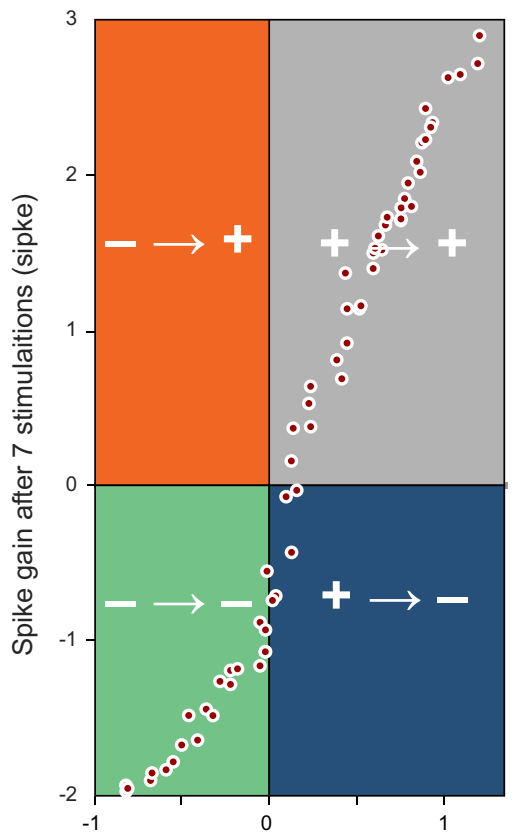

Spike gain after 3 stimulations (spike)

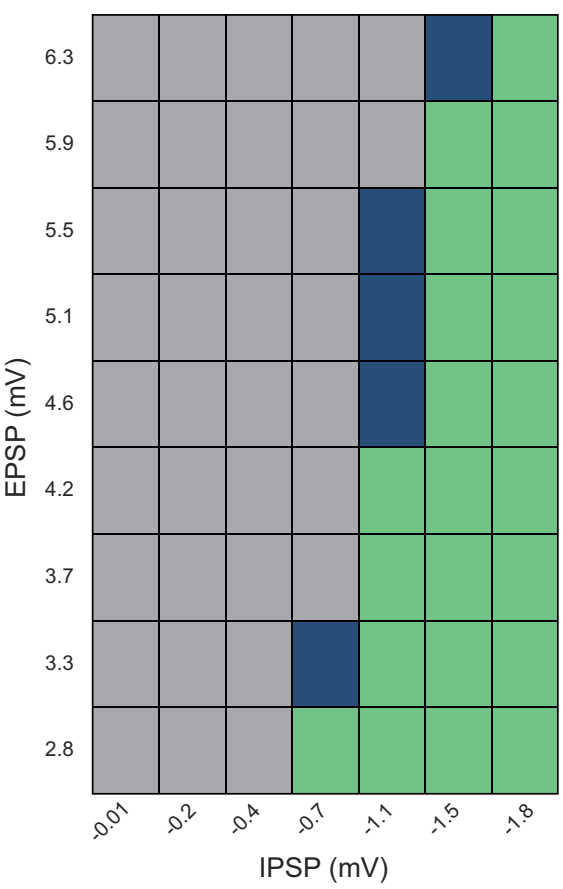

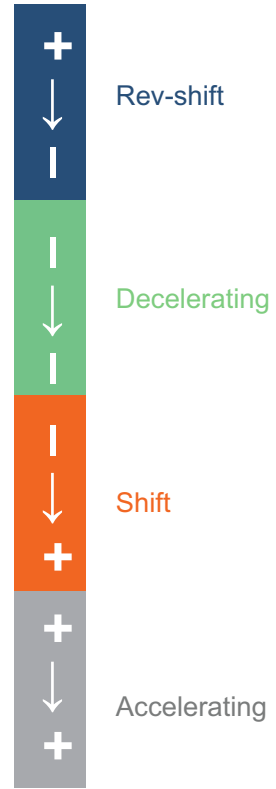

$\mathrm{EPSP}=2.3 \mathrm{mV} \quad \mathrm{IPSP}=-1 \mathrm{mV}$

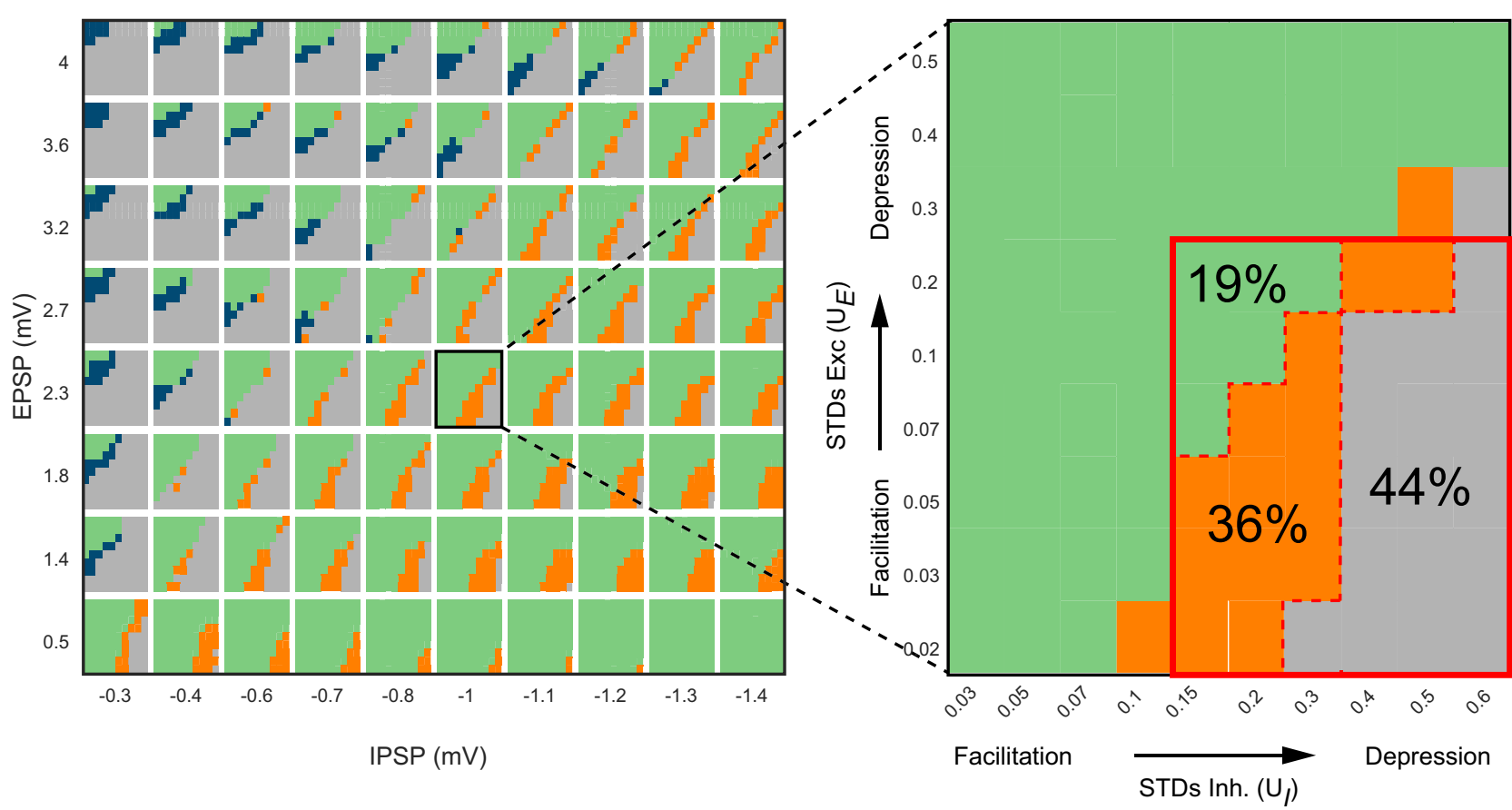

Figure 6. The shift group of PC responses requires STD at excitatory and inhibitory pathways. $A$, Left, Plot of the spike gain elicited by $7 \mathrm{GrC}$ stimuli against spike gain for 3 stimuli when GrC-PC and MLI-PC synapses are static (no STD). The four possible scenarios for the spike gain are marked in different colors. Gray and green represents no change in the sign of the spike gain between 3 and $7 \mathrm{GrC}$ stimuli; gray and green correspond to accelerating and decelerating PC response groups, respectively. Blue and orange represents change in the sign of the spike gain; blue and orange correspond to reverse-shift and shift $P C$ response groups, respectively. Each white dot indicates spike gains for different combinations of $E$ and $I$. The absence of any points in the orange quadrant shows that, without STD, it is not possible to observe negative spike gains for $3 \mathrm{GrC}$ stimuli then positive for 7 stimuli (i.e., the shift group of $\mathrm{PC}$ responses is absent). Middle, PC response group as a function of E and I for static synapses. For no combination of EPSP and IPSP amplitude did we obtain a shift in the spike gain as observed in in vitro experiments. $B$, Evolution of the sign of the spike gain with dynamic synapses (with STD) as a function of EPSP ( $y$ axis) and IPSP ( $x$ axis) amplitudes (left) when GrC stimulations switch from 3 to $7 \mathrm{GrC}$ stimulations. Inset, Inner rectangles represent

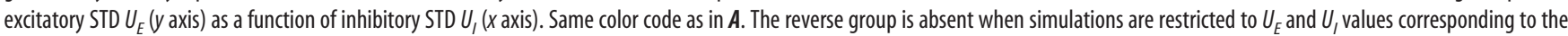
physiological range observed in our recordings (red rectangle, Inset). One rectangle has been highlighted to illustrate the influence of STD of excitation ( $y$ axis) and inhibition ( $x$ axis) on the behavior of the $\mathrm{PC}$ response. 
A

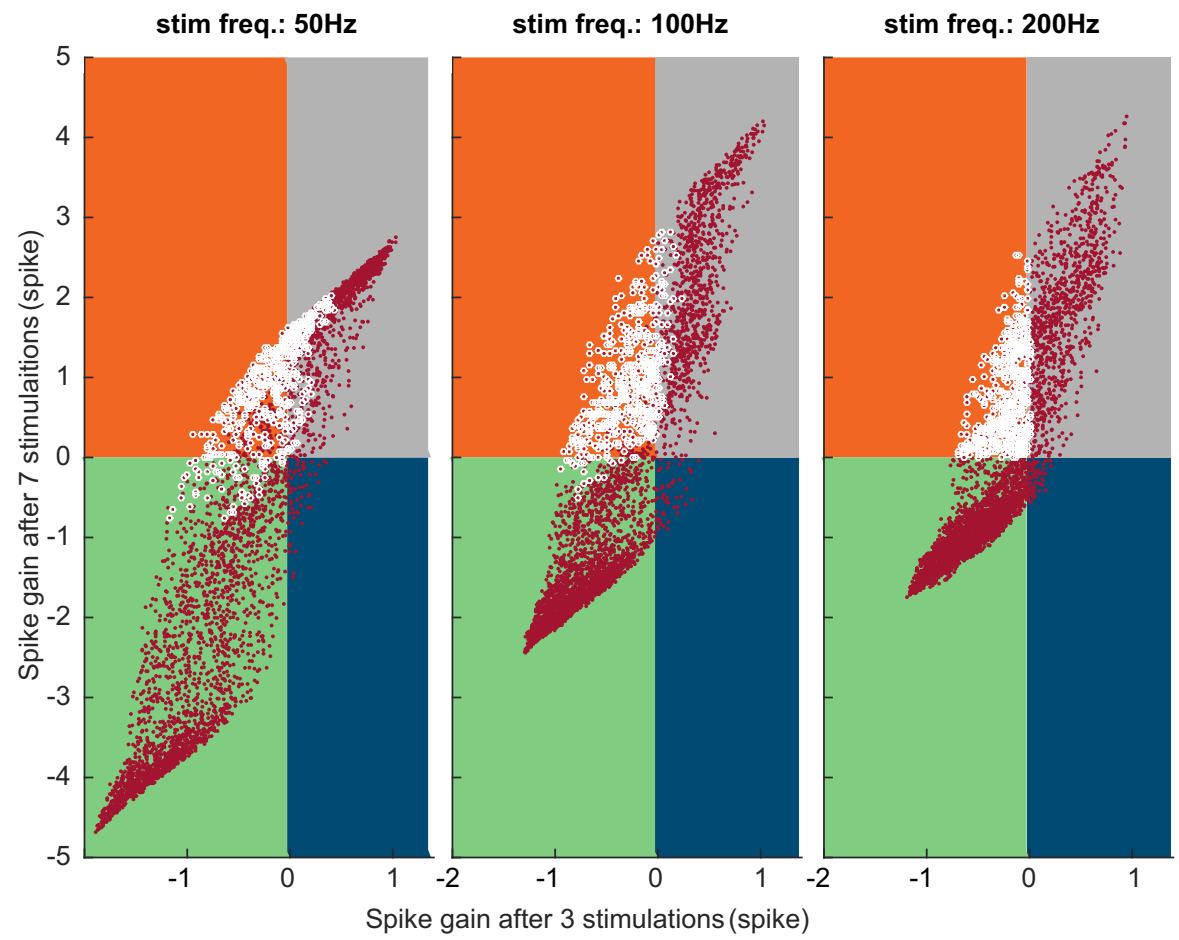

B
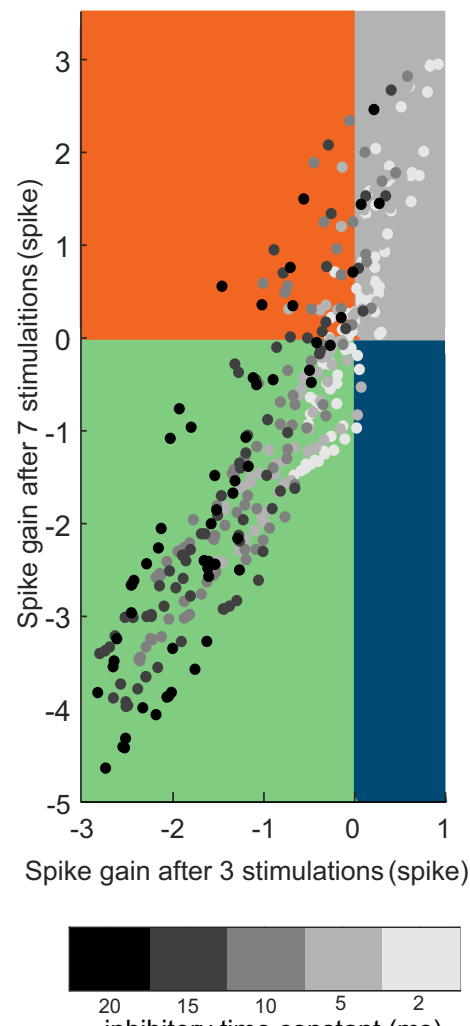

inhibitory time constant (ms)

Figure 7. Effect of the inhibitory decay time constant and stimulus frequency on the spike gain evolution. $A$, Evolution of the sign of the spike gain at varying $\operatorname{Gr} C$ input frequency $(50,100$, and $200 \mathrm{~Hz}$ ). Each panel represents spike gain for $7 \mathrm{GrC}$ stimuli plotted against the spike gain for 3 stimuli. The four possible scenarios for the spike gain are marked in different colors (same color code as in Fig. 6). Each dot indicates spike gain for different combinations of E, I, and STD parameters (same range as Fig. 6). For all 3 frequencies, we observed shift behavior in PC response. White circles represent simulation parameters leading to a shift behavior at $200 \mathrm{~Hz}$. B, Evolution of the sign of the spike gain at varying time constant of inhibition for a subset of E, I, and STD parameters. Each dot indicates spike gain for different combinations of E, I, STD parameters and inhibitory decay time constant (marked in different gray shaded; see color bar). Increasing the decay time constant of synaptic inhibition enhances the magnitude of the spike gain but does not affect the occurrence of the shift group. Here $E, I$, and STD parameters spanned the same range as in $A$, but we used a coarse grained sampling of these parameters so as to avoid cluttering.

cells, $36 \%$ of shift cells, and 19\% of decelerating cells (Fig. $6 B$, right, red rectangle indicates the biologically realistic range of STD parameters panel). This distribution is similar to our experimental observations (Fig. 3). By contrast, depression of excitation and facilitation of inhibition resulted in the opposite scenario for various $\mathrm{E}$ and I set of values (Fig. 6B, blue regions). However, when the space of parameters was restricted to the experimentally observed values of STD $\left(0.02<U_{E}<0.2\right.$ and $0.15<U_{I}<0.6$ defined by the upper and lower range of Fig. 4), the latter scenario was almost absent, and the simulation predicted the same 3 groups as in the experimental dataset (Fig. $6 B$, red rectangle).

We then assessed whether varying other model and input parameters in addition to $\mathrm{E} / \mathrm{I}$ and STD parameters affected the spike gain and the occurrence of the shift group. The accelerating, decelerating, and shift type spike gain could be observed at lower frequencies, down to $50 \mathrm{~Hz}$ (Fig. $7 \mathrm{~A}$ ) and for a wide range of time constants of the inhibitory synapses (Fig. $7 B$ ). These findings suggest that the shift group is a robust feature of PC integration of GrC rate code as long as the synapses are endowed with STD. Thus, the simulations confirm that the combination of E, I, and STD is necessary and sufficient for the accurate description of the PC discharge following GrC stimulation. Moreover, we con- firmed that the structure of the PC spike train is strongly controlled by the number of spikes in the GrC burst. Finally, our model demonstrates that shift cell behavior requires facilitating excitation and depressing inhibition as observed in the experimental dataset.

\section{Discussion}

A large diversity of Purkinje cell response elicited by GrCs

In this study, we demonstrated that, although the sensorimotor MF-GrC-MLI-PC input pathway in the cerebellum is anatomically organized as a classical FFI microcircuit, specific operational rules for synaptic excitation and inhibition lead to a wide diversity in PC discharges in response to GrCs stimulation: from an increase in firing rate to a complete shutdown of the discharge. The versatility of the PC discharge was enhanced by an interplay of excitatory and inhibitory STD that regulates vesicular release at individual connections. Indeed, in the MF-GrC-PC pathway, GrCs can fire at several hundred $\mathrm{Hz}$ during sensorimotor processing in different areas of the cerebellar cortex (Chadderton et al., 2004; Jörntell and Ekerot, 2006; Arenz et al., 2008). As high firing rates scale up the STD (Atluri and Regehr, 1996; Pedroarena and Schwarz, 2003; Hallermann et al., 2010; Valera et al., 2012), E/I balance is highly affected by burst duration. 
Several in vivo and in vitro studies (Eccles et al., 1967; Brunel et al., 2004; Mittmann et al., 2005) have previously reported a correlation between $\mathrm{E}$ and I synaptic weights in the MF-GrC-PC FFI pathway, suggesting that inhibition may control the temporal window of PC discharge (Mittmann et al., 2005). In our results, no correlation was observed between EPSC and IPSC amplitude elicited by GrCs, and PC discharges were not determined solely by E/I balance. This discrepancy can be explained by the use of compound parallel fiber stimulation in previous studies. Such protocols simultaneously excite thousands of fibers from multiple heterogeneous GrC-PC and GrC-MLI-PC pathways. However, in a recent study, we have demonstrated that PCs or MLIs at the same location may be driven by different clusters of GrCs. This suggests, for example, that $\mathrm{GrC}$ activation in a given zone of the cerebellar cortex might lead to PCs inhibition (Valera et al., 2016), questioning the basic postulate that at a population-level GrC-induced excitation and inhibition are always highly correlated. The interplay between long-term synaptic plasticity observed at the excitatory (GrC-PC and GrC-MLI) and inhibitory (MLI-PC) connections in the GrC-MLI-PC pathway lead to the description of specific and complex influence on PC discharge (Mittmann et al., 2004; Smith and Otis, 2005; Steuber et al., 2007; Wang et al., 2009; Bing et al., 2015; ten Brinke et al., 2015). Wholecell patch-clamp in vivo recordings in awake animals confirmed both the linear relationship between PC firing rate and the independent regulation of E and I targeting PCs (Jelitai et al., 2016). These particular features of the FFI in the cerebellar cortex allow for a precise modulation of the spontaneously active PCs. When combined with high-frequency burst stimulation (from 50 to 200 $\mathrm{Hz}$, as shown in Fig. 7) of GrC inputs and STD, here we have demonstrated an unexpected influence of $\mathrm{GrC}$ stimulation on $\mathrm{PC}$ discharge. Despite the heterogeneity in STD parameters of E and I synapses (Fig. 4) (Perkel et al., 1990; Llano et al., 1991; Isope and Barbour, 2002; Bao et al., 2010; Valera et al., 2012), inhibition always depresses while excitation facilitates when bursts lengthen. These STD lead to a systematic increase in E/I ratios and a switch in the sign of the overall effect on $\mathrm{PC}$ firing rate for a wide range of initial E/I ratio. Indeed, in $41 \%$ of the experiments (in the shift group), the sign of the spike gain switched from inhibitory to excitatory when burst duration increased from 3 to 7 stimuli. These findings strongly suggest that the interplay between E, I, and STD can encode burst duration through a nonlinear spike gain modulation, supporting the idea of a temporal-to-rate code transformation. For the accelerating and decelerating groups, a monotonic change in the spike gain was observed similar to the monotonic increase in PC discharge with GrC input strengths (Walter and Khodakhah, 2006). Moreover, our computational model revealed that all the PC discharges observed in the experimental dataset, including the switch in the spike gain, can be explained solely by the interplay between E, I, and STD parameters. The model confirmed that depression of inhibitory synapses is essential to generate output similar to the shift cells. Excitatory input to the shift cell could be of both facilitating (for weak synapses) and depressing type (for strong synapses) and PCs receiving only static synapses cannot exhibit the shift cell behavior (Fig. 6). Hence, networks endowed with synaptic STD may encode longer and shorter stimuli differently. The multiplexing of the postsynaptic weights (E and I; rate coding) with the temporal and frequency-dependent properties of STD, a presynaptic feature, at the GrC-PC and GrC-MLI-PC synapses may then extend $\mathrm{PC}$ encoding possibilities and information transfer to the downstream cerebellar nuclei.

\section{Functional implications}

Movement encoding by both negative and positive changes in spike gain in PC discharges have been observed in many studies (see, e.g., Thach, 1968; Armstrong and Edgley, 1984; Thier et al., 2000; Herzfeld et al., 2015; Chen et al., 2016). In primates, rapid eye movements (saccades) are coded by a dual population of PCs, with one group increasing its firing rate while the other decreases it (Herzfeld et al., 2015). Similarly, in rodents, whisker position during voluntary movements is encoded by the modulation of PCs from an acceleration to a complete shutdown (Chen et al., 2016). Then, the FFI circuit in association with the direct GrC-PC excitatory pathway of the cerebellar cortex takes over the adjustment of the set point frequency of PCs that controls the movement.

Presynaptic STD properties could also account for some features of the encoding of motor actions by PCs. Interestingly at the MF-GrC connection, pathway-specific STD allowing temporal coding of multimodal sensory inputs has been recently observed (Chabrol et al., 2015). In this study, the delay of the first spike and the frequency of discharge of $\mathrm{GrCs}$ encode a specific combination of MF and input frequency. Therefore, for short MF bursts $(<10$ spikes), GrC burst duration may also reflect MF identity. The nonlinear encoding of GrC burst duration by PCs shown in this study would then transmit MF input diversity to the output stage of the cerebellar cortex. These results were obtained for very high input firing rates as often observed in vivo (Chadderton et al., 2004; Jörntell and Ekerot, 2006; Arenz et al., 2008) for which the effect of STD is very strong. But we show that the results are qualitatively similar even when stimulation frequency is reduced down to $50 \mathrm{~Hz}$ (Fig. 7), a frequency observed in other cerebellar regions coding for more continuous sensorimotor stimuli (e.g., in the vestibular system). As expected, a progressive increase in the stimulation frequency from 50 to $200 \mathrm{~Hz}$ increases the incidence of shift behavior and variability in the spike pattern of PCs. Typically, STD is observed for frequencies $>20 \mathrm{~Hz}$ (Valera et al., 2012), so we hypothesize that the behavior of the GrC-MLI-PC system will be akin to the static synapse case when stimulation frequency is $<20 \mathrm{~Hz}$.

The combination of presynaptic and postsynaptic plasticity might expand the dynamic range of the PCs by including a nonlinear dimension that would increase the number of features encoded by the cerebellar cortex. Consistent with this, in a recent study, in which PCs were recorded in vivo during locomotion (Sauerbrei et al., 2015), not only step-locked PC firing rates were observed, but also a correlation between the variability of the firing rate around the step-locked discharge and features of the behavior have been established. Concretely, the trial-by-trial jitter in the PC discharge during the step cycle carried information related to speed, roll, and tilt, and the precise pattern of discharge was found behaviorally relevant. These properties require fast modulation of PC discharge embedded in an averaged firing rate. Therefore, the combination of E/I balance and STD leading to a large diversity of PC discharges observed in our dataset might underlie this precise control of movements. In conclusion, both the experimental data and computational model described in this study suggest that the interplay between E/I balance and STD allows PCs to multiplex rate- and timingbased coding strategy.

\section{References}

Arenkiel BR, Peca J, Davison IG, Feliciano C, Deisseroth K, Augustine GJ, Ehlers MD, Feng G (2007) In vivo light-induced activation of neural circuitry in transgenic mice expressing channelrhodopsin-2. Neuron 54: 205-218. CrossRef Medline 
Arenz A, Silver RA, Schaefer AT, Margrie TW (2008) The contribution of single synapses to sensory representation in vivo. Science 321:977-980. CrossRef Medline

Armstrong DM, Edgley SA（1984） Discharges of Purkinje cells in the paravermal part of the cerebellar anterior lobe during locomotion in the cat. J Physiol 352:403-424. CrossRef Medline

Atluri PP, Regehr WG (1996) Determinants of the time course of facilitation at the granule cell to Purkinje cell synapse. J Neurosci 16:5661-5671. CrossRef Medline

Bao J, Reim K, Sakaba T (2010) Target-dependent feedforward inhibition mediated by short-term synaptic plasticity in the cerebellum. J Neurosci 30:8171-8179. CrossRef Medline

Bartley AF, Dobrunz LE (2015) Short-term plasticity regulates the excitation/inhibition ratio and the temporal window for spike integration in CA1 pyramidal cells. Eur J Neurosci 41:1402-1415. CrossRef Medline

Bing YH, Wu MC, Chu CP, Qiu DL (2015) Facial stimulation induces longterm depression at cerebellar molecular layer interneuron-Purkinje cell synapses in vivo in mice. Front Cell Neurosci 9:214. CrossRef Medline

Blot A, de Solages C, Ostojic S, Szapiro G, Hakim V, Léna C (2016) Timeinvariant feed-forward inhibition of Purkinje cells in the cerebellar cortex in vivo. J Physiol 594:2729-2749. CrossRef Medline

Bower JM, Woolston DC (1983) Congruence of spatial organization of tactile projections to granule cell and Purkinje cell layers of cerebellar hemispheres of the albino rat: vertical organization of cerebellar cortex. J Neurophysiol 49:745-766. CrossRef Medline

Brunel N, Hakim V, Isope P, Nadal JP, Barbour B (2004) Optimal information storage and the distribution of synaptic weights: perceptron versus Purkinje cell. Neuron 43:745-757. CrossRef Medline

Buzsáki G (1984) Feed-forward inhibition in the hippocampal formation. Prog Neurobiol 22:131-153. CrossRef Medline

Chabrol FP, Arenz A, Wiechert MT, Margrie TW, DiGregorio DA (2015) Synaptic diversity enables temporal coding of coincident multisensory inputs in single neurons. Nat Neurosci 18:718-727. CrossRef Medline

Chadderton P, Margrie TW, Häusser M (2004) Integration of quanta in cerebellar granule cells during sensory processing. Nature 428:856-860. CrossRef Medline

Chen S, Augustine GJ, Chadderton P (2016) The cerebellum linearly encodes whisker position during voluntary movement. Elife 5:1-16. CrossRef Medline

Destexhe A, Rudolph M, Paré D (2003) The high-conductance state of neocortical neurons in vivo. Nat Rev Neurosci 4:739-751. CrossRef Medline

Eccles JC, Ito M, Szentagotai J (1967) The cerebellum as neuronal machine. Berlin, Germany: Springer-Verlag.

Gabernet L, Jadhav SP, Feldman DE, Carandini M, Scanziani M (2005) Somatosensory integration controlled by dynamic thalamocortical feedforward inhibition. Neuron 48:315-327. CrossRef Medline

Garcia S, Fourcaud-Trocmé N (2009) OpenElectrophy: an electrophysiological data- and analysis-sharing framework. Front Neuroinform 3:14. CrossRef Medline

Hallermann S, Fejtova A, Schmidt H, Weyhersmüller A, Silver RA, Gundelfinger ED, Eilers J (2010) Bassoon speeds vesicle reloading at a central excitatory synapse. Neuron 68:710-723. CrossRef Medline

Häusser M, Clark BA (1997) Tonic synaptic inhibition modulates neuronal output pattern and spatiotemporal synaptic integration. Neuron 19:665678. CrossRef Medline

Herzfeld DJ, Kojima Y, Soetedjo R, Shadmehr R (2015) Encoding of action by the Purkinje cells of the cerebellum. Nature 526:439-442. CrossRef Medline

Husson F, Lê S, Pages J (2016) Analyse de données avec R, Ed 2. Rennes, France: Universitaires de Rennes.

Isaacson JS, Scanziani M (2011) How inhibition shapes cortical activity. Neuron 72:231-243. CrossRef Medline

Isope P, Barbour B (2002) Properties of unitary granule cell $\rightarrow$ Purkinje cell synapses in adult rat cerebellar slices. J Neurosci 22:9668-9678. CrossRef Medline

Jackman SL, Regehr WG (2017) The mechanisms and functions of synaptic facilitation. Neuron 94:447-464. CrossRef Medline

Jaeger D, Bower JM (1994) Prolonged responses in rat cerebellar Purkinje cells following activation of the granule cell layer: an intracellular in vitro and in vivo investigation. Exp Brain Res 100:200-214. Medline

Jelitai M, Puggioni P, Ishikawa T, Rinaldi A, Duguid I (2016) Dendritic excitation-inhibition balance shapes cerebellar output during motor behaviour. Nat Commun 7:13722. CrossRef Medline

Jörntell H, Ekerot CF (2006) Properties of somatosensory synaptic integration in cerebellar granule cells in vivo. J Neurosci 26:11786-11797. CrossRef Medline

Katzner S, Busse L, Carandini M (2011) GABA $_{\mathrm{A}}$ inhibition controls response gain in visual cortex. J Neurosci 31:5931-5941. CrossRef Medline

Kremkow J, Aertsen A, Kumar A (2010) Gating of signal propagation in spiking neural networks by balanced and correlated excitation and inhibition. J Neurosci 30:15760-15768. CrossRef Medline

Kumbhare D, Baron MS (2015) A novel tri-component scheme for classifying neuronal discharge patterns. J Neurosci Methods 239:148-161. CrossRef Medline

Lê S, Josse J, Husson F (2008) FactoMineR: an R package for multivariate analysis. J Stat Softw 25:1-18.

Llano I, Marty A, Armstrong CM, Konnerth A (1991) Synaptic- and agonistinduced excitatory currents of Purkinje cells in rat cerebellar slices. J Physiol 434:183-213. CrossRef Medline

Markram H, Tsodyks M (1996) Redistribution of synaptic efficacy between neocortical pyramidal neurons. Nature 382:807-810. CrossRef Medline

Mittmann W, Häusser M (2007) Linking synaptic plasticity and spike output at excitatory and inhibitory synapses onto cerebellar Purkinje cells. J Neurosci 27:5559-5570. CrossRef Medline

Mittmann W, Chadderton P, Häusser M (2004) Neuronal microcircuits: frequency-dependent flow of inhibition. Curr Biol 14:R837-R839. CrossRef Medline

Mittmann W, Koch U, Häusser M (2005) Feed-forward inhibition shapes the spike output of cerebellar Purkinje cells. J Physiol 563:369-378. CrossRef Medline

Pedroarena CM, Schwarz C (2003) Efficacy and short-term plasticity at GABAergic synapses between Purkinje and cerebellar nuclei neurons. J Neurophysiol 89:704-715. CrossRef Medline

Perkel DJ, Hestrin S, Sah P, Nicoll RA (1990) Excitatory synaptic currents in Purkinje cells. Proc Biol Sci 241:116-121. CrossRef Medline

Rancz EA, Ishikawa T, Duguid I, Chadderton P, Mahon S, Häusser M (2007) High-fidelity transmission of sensory information by single cerebellar mossy fibre boutons. Nature 450:1245-1248. CrossRef Medline

Sauerbrei BA, Lubenov EV, Siapas AG (2015) Structured variability in Purkinje cell activity during locomotion. Neuron 87:840-852. CrossRef Medline

Saviane C, Silver RA (2006) Fast vesicle reloading and a large pool sustain high bandwidth transmission at a central synapse. Nature 439:983-987. CrossRef Medline

Schmidt H, Brachtendorf S, Arendt O, Hallermann S, Ishiyama S, Bornschein G, Gall D, Schiffmann SN, Heckmann M, Eilers J (2013) Nanodomain coupling at an excitatory cortical synapse. Curr Biol 23:244-249. CrossRef Medline

Shepherd G, Grillner S (2010) Handbook of Brain Microcircuits, Ed 1: Oxford, UK: Oxford UP.

Shin SL, Hoebeek FE, Schonewille M, De Zeeuw CI, Aertsen A, De Schutter E (2007) Regular patterns in cerebellar Purkinje cell simple spike trains. PLoS One 2:e485. CrossRef Medline

Smith SL, Otis TS (2005) Pattern-dependent, simultaneous plasticity differentially transforms the input-output relationship of a feedforward circuit. Proc Natl Acad Sci U S A 102:14901-14906. CrossRef Medline

Steuber V, Mittmann W, Hoebeek FE, Silver RA, De Zeeuw CI, Häusser M, De Schutter E (2007) Cerebellar LTD and pattern recognition by Purkinje cells. Neuron 54:121-136. CrossRef Medline

Stevens CF, Wang Y (1995) Facilitation and depression at single central synapses. Neuron 14:795-802. CrossRef Medline

ten Brinke MM, Boele HJ, Spanke JK, Potters JW, Kornysheva K, Wulff P, IJpelaar AC, Koekkoek SK, De Zeeuw CI (2015) Evolving models of Pavlovian conditioning: cerebellar cortical dynamics in awake behaving mice. Cell Rep 13:1977-1988. CrossRef Medline

Thach WT (1968) Discharge of Purkinje and cerebellar nuclear neurons during rapidly alternating arm movements in the monkey. J Neurophysiol 31:785-797. CrossRef Medline

Thier P, Dicke PW, Haas R, Barash S (2000) Encoding of movement time by populations of cerebellar Purkinje cells. Nature 405:72-76. CrossRef Medline

Tsodyks MV, Markram H (1997) The neural code between neocortical py- 
ramidal neurons depends on neurotransmitter release probability. Proc Natl Acad Sci U S A 94:719-723. CrossRef Medline

Valera AM, Doussau F, Poulain B, Barbour B, Isope P (2012) Adaptation of granule cell to Purkinje cell synapses to high-frequency transmission. J Neurosci 32:3267-3280. CrossRef Medline

Valera AM, Binda F, Pawlowski SA, Dupont JL, Casella JF, Rothstein JD, Poulain B, Isope P (2016) Stereotyped spatial patterns of functional synaptic connectivity in the cerebellar cortex. Elife 5:e09862. CrossRef Medline

van Beugen BJ, Gao Z, Boele HJ, Hoebeek F, De Zeeuw CI (2013) High frequency burst firing of granule cells ensures transmission at the parallel fiber to Purkinje cell synapse at the cost of temporal coding. Front Neural Circuits 7:95. CrossRef Medline

van Kan PL, Gibson AR, Houk JC (1993) Movement-related inputs to in- termediate cerebellum of the monkey. J Neurophysiol 69:74-94. CrossRef Medline

Walter JT, Khodakhah K (2006) The linear computational algorithm of cerebellar Purkinje cells. J Neurosci 26:12861-12872. CrossRef Medline

Wang X, Chen G, Gao W, Ebner T (2009) Long-term potentiation of the responses to parallel fiber stimulation in mouse cerebellar cortex in vivo. Neuroscience 5:713-722. CrossRef Medline

Wehr M, Zador AM (2003) Balanced inhibition underlies tuning and sharpens spike timing in auditory cortex. Nature 426:442-446. CrossRef Medline

Wilms CD, Häusser M (2015) Reading out a spatiotemporal population code by imaging neighbouring parallel fibre axons in vivo. Nat Commun 6:6464. CrossRef Medline

Zucker RS, Regehr WG (2002) Short-term synaptic plasticity. Annu Rev Physiol 64:355-405. CrossRef Medline 